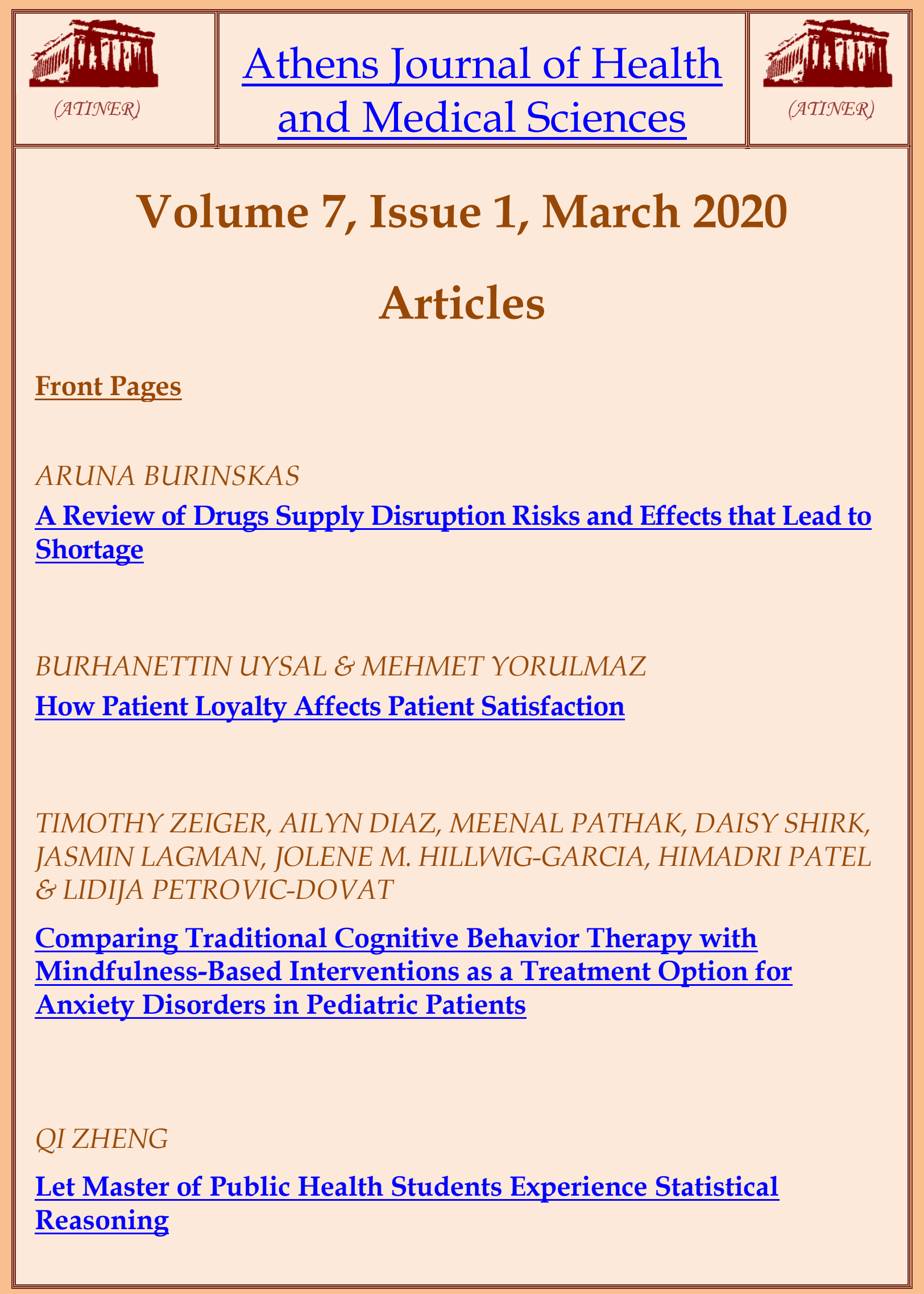






$(A T I \mathcal{N} E R)$

\section{Mission}

ATINER is an Athens-based World Association of Academics and Researchers based in Athens. ATINER is an independent and non-profit Association with a Mission to become a forum where Academics and Researchers from all over the world can meet in Athens, exchange ideas on their research and discuss future developments in their disciplines, as well as engage with professionals from other fields. Athens was chosen because of its long history of academic gatherings, which go back thousands of years to Plato's Academy and Aristotle's Lyceum. Both these historic places are within walking distance from ATINER's downtown offices. Since antiquity, Athens was an open city. In the words of Pericles, Athens"... is open to the world, we never expel a foreigner from learning or seeing". ("Pericles' Funeral Oration", in Thucydides, The History of the Peloponnesian War). It is ATINER's mission to revive the glory of Ancient Athens by inviting the World Academic Community to the city, to learn from each other in an environment of freedom and respect for other people's opinions and beliefs. After all, the free expression of one's opinion formed the basis for the development of democracy, and Athens was its cradle. As it turned out, the Golden Age of Athens was in fact, the Golden Age of the Western Civilization. Education and (Re)searching for the 'truth' are the pillars of any free (democratic) society. This is the reason why Education and Research are the two core words in ATINER's name. 
The Athens Journal of Health and Medical Sciences

ISSN NUMBER: 2241-8229 - DOI: 10.30958/ajh

Volume 7, Issue 1, March 2020

Download the entire issue $(\underline{\mathrm{PDF}})$

Front Pages $\quad i-x$

A Review of Drugs Supply Disruption Risks and Effects 1 that Lead to Shortage

Aruna Burinskas

How Patient Loyalty Affects Patient Satisfaction

Burhanettin Uysal \& Mehmet Yorulmaz

Comparing Traditional Cognitive Behavior Therapy with Mindfulness-Based Interventions as a Treatment Option for Anxiety Disorders in Pediatric Patients

Timothy Zeiger, Ailyn Diaz, Meenal Pathak, Daisy Shirk, Jasmin Lagman, Jolene M. Hillwig-Garcia, Himadri Patel $\mathcal{E}$ Lidija Petrovic-Dovat

Let Master of Public Health Students Experience Statistical Reasoning

Qi Zheng 


\section{Athens Journal of Health and Medical Sciences Editorial and Reviewers' Board}

Editors

- Dr. Zoe Boutsioli, Vice President of Publications \& Research, ATINER \& President, Athens Centre for Greek \& International Education (ACEGIE), zb5@atiner.gr.

- Dr. John Moraros, Academic Member, ATINER \& Associate Professor, University of Saskatchewan, Canada, john.moraros@usask.ca.

- Dr. Douglas E. Angus, Full Professor, Telfer School of Management, University of Ottawa, Canada, Angus@telfer.uottawa.ca.

- Dr. George Zahariadis, Academic Member, ATINER \& Associate Professor, Faculty of Medicine, Memorial University of Newfoundland, Canada, george.zahariadis@easternhealth.ca.

- Dr. Apostolos Tsiachristas, Academic Member, ATINER \& Senior Researcher, Health Economics Research Centre, Nuffield Dept. of Population Health, University of Oxford, UK, apostolos.tsiachristas@dph.ox.ac.uk.

- Dr. Paul Contoyannis, Head, Health Economics and Management Research Unit, ATINER \& Associate Professor, Faculty of Social Sciences, Department of Economics, McMaster University, Canada, contoyp@mcmaster.ca.

\section{Editorial Board}

- Dr. Steven M. Oberhelman, Associate Dean and Jr. Professor of Liberal Arts, Texas A\&M University, USA, s-oberhelman@tamu.edu.

- Dr. Sandra Bassendowski, Professor, College of Nursing, University of Saskatchewan, Canada, sandra.bassendowski@usask.ca.

- Dr. Sabine Bohnet-Joschko, Walcker Professor of Management and Innovation in Healthcare, Faculty of Management and Economics, Witten-Herdecke University, Germany, Sabine.Bohnet-Joschko@uniwh.de.

- Dr. H R Chitme, Academic Member, ATINER \& Professor, Oman Medical College, Sultanate of Oman, hrchitme@rediffmail.com.

- Dr. Mihajlo Jakovljevic, Academic Member, ATINER \& Professor, University of Kragujevac, Serbia, sidartagothama@gmail.com.

- Dr. Elizabeth Poster, Professor, College of Nursing and Health Innovation, University of Texas Arlington, USA, poster@exchange.uta.edu.

- Dr. Paolo Ricci, Professor, University of Bologna, Italy, apricci@earthlink.net.

- Dr. Iga Rudawska, Head and Professor, Chair of Health Economics, Faculty of Economics and Management, University of Szczecin, Poland, igita@wneiz.pl.

- Dr. Mary Tsouroufli, Academic Member, ATINER \& Reader in Education, University of Wolverhampton, UK, M.Tsouroufli@wlv.ac.uk.

- Dr. Yelena Bird, Academic Member, ATINER \& Associate Professor, University of Saskatchewan, Canada, yelena.bird@usask.ca.

- Dr. Donald Rob Haley, Associate Professor, Health Administration Program Department of Public Health, Brooks College of Health, University of North Florida, USA, rhaley@unf.edu.

- Dr. Jarmila Kristová, Associate Professor, Slovak Medical University in Bratislava, Slovakia, jarmila.kristova@szu.sk.

- Dr. Amardeep Thind, Academic Member, ATINER \& Professor and Director, Western University, Canada, athind2@uwo.ca.

- Dr. Reza Yousefi, Associate Professor of Biochemistry, Department of Biology, Shiraz University, Iran,ryousefi@shirazu.ac.ir.

- Dr. Yanzhong Huang, Senior Fellow for Global Health, Council on Foreign Relations, USA \& Professor and Director for Global Health Studies, School of Diplomacy and International Relations, 
Seton Hall University, USA, YHuang@cfr.org.

- Dr. David P. Keys, Associate Professor, Department of Criminal Justice, New Mexico State, USA, davekeys@nmsu.edu.

- Dr. Christiaan Lako, Academic Member, ATINER \& Associate Professor, Department of Public Administration, Radboud University Nijmegen, The Netherlands, c.lako@fm.ru.nl.

- Dr. Emmanouil Mentzakis, Academic Member, ATINER \& Associate Professor, Department of Economics, University of Southampton, UK, E.Mentzakis@soton.ac.uk.

- Dr. Laurence G. Rahme, Associate Professor, Department of Surgery, Microbiology and Immunobiology, Harvard Medical School, Boston, Massachusetts \& Director of Molecular Surgical Laboratory, Burns Unit, Department of Surgery, Massachusetts General Hospital, USA, rahme@molbio.mgh.harvard.edu.

- Dr. Peter Erwin Spronk, Internist-Intensivist, FCCP, Director of Research of Intensive Care Medicine, Medical Director Intensive Care, Gelre Hospitals, Apeldoorn, The Netherlands, pspronk@chello.nl.

- Dr. Roseane Maria Maia Santos, Academic Member, ATINER \& Associate Professor, Pharmaceutical Sciences Department, South University School of Pharmacy, USA, rsantos@southuniversity.edu.

- Dr. Fiona Timmins, Associate Professor, School of Nursing and Midwifery, Trinity College Dublin, Ireland, timminsf@tcd.ie.

- Dr. Eleni L. Tolma, Associate Professor, Department of Health Promotion Sciences, College of Public Health, University of Oklahoma Health Sciences Center, USA, eleni-tolma@ouhsc.edu.

- Dr. Amalia Tsiami, Associate Professor, London School of Hospitality and Tourism, University of West London, UK, Amalia.Tsiami@uwl.ac.uk.

- Dr. Tibebe Woldemariam, Academic Member, ATINER \& Associate Professor, College of Pharmacy, California Northstate University, USA, TWoldemariam@cnsu.edu.

- Dr. Alberto Zamora, Associate Professor, School of Medicine, University of Girona \& Internal Department, Hospital of Blanes, Girona, Spain, azamorac.zamora@gmail.com.

- Dr. Alain Touwaide, Scientific Director, Institute for the Preservation of Medical Traditions History of Sciences \& Department of Botany, National Museum of Natural History, Smithsonian Institution, USA, atouwaide@hotmail.com.

- Dr. Anita Meldrum, Assistant Head of Department, Sustainable Environments \& Communities, School of Engineering \& the Built Environment, Glasgow Caledonian University, Glasgow, Scotland, Anita.Meldrum@gcu.ac.uk.

- Dr. Jennie De Gagne, Assistant Professor, School of Nursing, Duke University, USA, jennie.degagne@duke.edu.

- Dr. Anna Hnatyszyn-Dzikowska, Academic Member, ATINER \& Assistant Professor, Department of Health Economics, Nicolaus Copernicus University in Torun, Poland, a.hnatyszyn@cm.umk.pl.

- Dr. Selini Katsaiti, Assistant Professor, Department of Economics and Finance, College of Business and Economics, United Arab Emirates University, UAE, Selini.katsaiti@uaeu.ac.ae.

- Dr. Zia-Ullah Khokhar, Assistant Professor in Chemistry, Institute of Biochemistry and Biotechnology, Punjab University, Lahore \& Govt. Islamia College, Gujranwala, Pakistan, zia2_khokhar@hotmail.com.

- Dr. Tammy Lampley, Assistant Professor, Assistant Program Director, Nurse Education Program, Sacred Heart University, USA, lampleyt@sacredheart.edu.

- Dr. Blazej Lyszczarz, Assistant Professor, Department of Public Health, Nicolaus Copernicus University, Poland, blazej@cm.umk.pl.

- Dr. Abeer Orabi, Assistant Professor, Women and Newborn Health Nursing, College of NursingJeddah, King Saud bin Abdulaziz University for Health Sciences, Kingdom of Saudi Arabia, orabiab@NGHA.MED.SA.

- Dr. Igor V. Pantic, Assistant Professor, Institute of Medical Physiology, School of Medicine, University of Belgrade, Serbia, igorpantic@gmail.com.

- Dr. Efrosini Papaconstantinou, Assistant Professor, Faculty of Health Sciences, University of Ontario Institute of Technology, Canada, Efrosini.Papaconstantinou@uoit.ca.

- Dr. Tara N. Turley-Stoulig, Instructor, Department of Biological Sciences, Southeastern Louisiana 
University, USA, tturley@selu.edu.

- Dr. Samah Anwar Mohamed Shalaby, Lecturer Critical Care and Emergency, Faculty of Nursing, Alexandria University, Egypt, samahanwar_2005@yahoo.com.

- Dr. Abraham Brown, Senior Lecturer, Division of Marketing, Nottingham Business School, Nottingham Trent University, UK, abraham.brown@ntu.ac.uk.

- Dr. Graeme Lockwood, Senior Lecturer in Law and Management, Department of Management, King's College London, UK, Graeme.lockwood@kcl.ac.uk.

- Dr. Nditsheni Jeanette Ramakuela, Academic Member, ATINER \& Senior Lecturer, University of Venda, South Africa, Nditsheni.Ramakuela@univen.ac.za.

- Dr. Melina Dritsaki, Academic Member, ATINER \& Senior Health Economist, Oxford Clinical Trials Unit, Nuffield Department of Orthopaedics, Rheumatology and Musculoskeletal Sciences , University of Oxford, UK, melina.dritsaki@ndorms.ox.ac.uk.

- Dr. Camelia Diaconu, Lecturer, University of Medicine and Pharmacy (UMF) Carol Davila, Faculty of General Medicine, Internal Medicine Clinic \& Internal medicine physician, Floreasca Clinical Emergency Hospital of Bucharest, Romania, camiluciemi@yahoo.com.

- Dr. Janet Dzator, Academic Member, ATINER \& Senior Lecturer, The University of Newcastle, NSW, Australia, janet.dzator@newcastle.edu.au.

- Dr. Efi Mantzourani, Academic Member, ATINER \& Lecturer in Pharmacy Practice, Leader of Undergraduate Placement-Based Learning, School of Pharmacy and Pharmaceutical Sciences, Cardiff University, UK, MantzouraniE1@cardiff.ac.uk.

- Dr. Helena Martins, Lecturer, Polytechnic of Porto \& University of Port, Portugal, helenagmartins@gmail.com.

- Dr. Catherine Wright, Academic Member, ATINER \& Lecturer and Principal Investigator, Glasgow Calcedonian University, UK, Catherine.Wright@gcu.ac.uk.

- Mr. Themba T. Sigudu, Lecturer of Environmental Health, Faculty of Health Sciences, University of Johannesburg, South Africa, thembas@uj.ac.za.

- Dr. Junhong Zhu, Academic Member, ATINER \& Postdoctoral Associate, Arthur Labatt Family School of Nursing, Western University, Canada, JUNHONGZHU66@hotmail.com.

- Dr. Noha El-Baz, Emergency and Critical Care Nursing Department, Faculty of Nursing, Alexandria University, Egypt, noha.elbaz@gmail.com.

- Dr. Audrey Marie Callum, Learning and Development Manager, SweetTree Home Care Services, London, UK, apeart.callum@gmail.com.

- Dr. Christos Andreou, Academic Member, ATINER \& Special Educational Officer, Nursing Department, Faculty of Health Sciences, Cyprus University of Technology, Cyprus, christos.andreou@cut.ac.cy.

- Dr. Peter Vermeir, Academic Member, ATINER \& Head ATP/Researcher, Ghent University Hospital/Ghent University, Belgium, Peter.Vermeir@uzgent.be.

- Dr. Kisalaya Basu, Academic Member, ATINER \& Senior Economic Advisor, Applied Research and Analysis Directorate, Canada, kisalaya.basu@canada.ca.

- Abdosaleh Jafari, PhD Student in Health Economics, Iran University of Medical Sciences, Tehran, Iran, abdosaleh.jafari@gmail.com.

- General Managing Editor of all ATINER's Publications: Ms. Afrodete Papanikou

- ICT Managing Editor of all ATINER's Publications: Mr. Kostas Spyropoulos

- Managing Editor of this Journal: Ms. Effie Stamoulara ( $\underline{\text { bio })}$

\section{Reviewers' Board}

Click Here 


\section{President's Message}

All ATINER's publications including its e-journals are open access without any costs (submission, processing, publishing, open access paid by authors, open access paid by readers etc.) and is independent of presentations at any of the many small events (conferences, symposiums, forums, colloquiums, courses, roundtable discussions) organized by ATINER throughout the year and entail significant costs of participating. The intellectual property rights of the submitting papers remain with the author. Before you submit, please make sure your paper meets the basic academic standards, which includes proper English. Some articles will be selected from the numerous papers that have been presented at the various annual international academic conferences organized by the different divisions and units of the Athens Institute for Education and Research. The plethora of papers presented every year will enable the editorial board of each journal to select the best, and in so doing produce a top-quality academic journal. In addition to papers presented, ATINER will encourage the independent submission of papers to be evaluated for publication.

The current issue is the first of the seventh volume of the Athens Journal of Health and Medical Sciences (AJHMS), published by the published by the Health \& Medical Sciences Division of ATINER

Gregory T. Papanikos

President

ATINER 


\section{Athens Institute for Education and Research}

\section{A World Association of Academics and Researchers}

19th Annual International Conference on Health Economics, Management \& Policy, 22-25 June 2020, Athens, Greece

The Health Economics \& Management Unit of ATINER will hold its 19 $^{\text {th }}$ Annual International

Conference on Health Economics, Management \& Policy, 22-25 June 2020, Athens,

Greece sponsored by the Athens Journal of Health and Medical Sciences. The aim of the conference is to bring together academics, researchers and professionals in health economics, management and policy. You may participate as stream leader, presenter of one paper, chair of a session or observer. Please submit a proposal using the form available (https://www.atiner.gr/2020/FORM-HEA.doc).

\section{Academic Members Responsible for the Conference}

- Dr. Paul Contoyannis, Head, Health Economics \& Management Unit, ATINER \& Associate Professor, McMaster University, Canada.

- Dr. Vickie Hughes, Director, Health \& Medical Sciences Division, ATINER \& Assistant Professor, School of Nursing, Johns Hopkins University, USA.

\section{Important Dates}

- Abstract Submission: 24 February 2019

- Acceptance of Abstract: 4 Weeks after Submission

- Submission of Paper: 25 Mav 2020

\section{Social and Educational Program}

The Social Program Emphasizes the Educational Aspect of the Academic Meetings of Atiner.

- Greek Night Entertainment (This is the official dinner of the conference)

- Athens Sightseeing: Old and New-An Educational Urban Walk

- Social Dinner

- Mycenae Visit

- Exploration of the Aegean Islands

- Delphi Visit

- Ancient Corinth and Cape Sounion

- More information can be found here: https://www.atiner.gr/social-program

\section{Conference Fees}

Conference fees vary from $400 €$ to $2000 €$

Details can be found at: https://www.atiner.gr/2019fees 


\section{Athens Institute for Education and Research}

A World Association of Academics and Researchers

\section{$8^{\text {th }}$ Annual International Conference on Health \& Medical Sciences 4-7 May 2020, Athens, Greece}

The Medicine Unit of ATINER is organizing its $\mathbf{8}^{\text {th }}$ Annual International Conference on Health \& Medical Sciences, 4-7 May 2020, Athens, Greece sponsored by the Athens Journal of Health and Medical Sciences. The aim of the conference is to bring together academics and researchers from all areas of health sciences, medical sciences and related disciplines. You may participate as stream leader, presenter of one paper, chair a session or observer. Please submit a proposal using the form available (https://www.atiner.gr/2019/FORM-HSC.doc).

\section{Important Dates}

- Abstract Submission: 23 March 2020

- Acceptance of Abstract: 4 Weeks after Submission

- Submission of Paper: 6 April 2020

\section{Academic Member Responsible for the Conference}

- Dr. Vickie Hughes, Director, Health \& Medical Sciences Research Division, ATINER \& Assistant Professor, School of Nursing, Johns Hopkins University, USA.

- Dr. Carol Anne Chamley, Head, Nursing Research Unit \& Associate Professor, School of Health and Social Care, London South Bank University UK.

- Dr. Andriana Margariti, Head, Medicine Research Unit, ATINER \& Lecturer, Centre for Experimental Medicine, Queen's University Belfast, U.K.

\section{Social and Educational Program}

The Social Program Emphasizes the Educational Aspect of the Academic Meetings of Atiner.

- Greek Night Entertainment (This is the official dinner of the conference)

- Athens Sightseeing: Old and New-An Educational Urban Walk

- Social Dinner

- Mycenae Visit

- Exploration of the Aegean Islands

- Delphi Visit

- Ancient Corinth and Cape Sounion

More information can be found here: https://www.atiner.gr/social-program

\section{Conference Fees}

Conference fees vary from $400 €$ to $2000 €$

Details can be found at: https://www.atiner.gr/2019fees 



\title{
A Review of Drugs Supply Disruption Risks and Effects that Lead to Shortage
}

\begin{abstract}
By Aruna Burinskas*
The objective of this paper is to give an estimation of drugs supply disruptive risks, which lead to a shortage. The literature analysis showed 15 drivers of supply disruptions and also, three main categories of risks (delays, forecasts and inventory), which produce a negative effect from what was intended; the return to low utilisation of supply service. These disruptions mean that if all required is not in place, shortage appears. There is a lack of knowledge of effects examination because not that many studies have been carried out from the perspective of drugs shortage. The study consists of two parts. The first part is dedicated to methods applicable for risks analysis, whereas the second one is dedicated to practical risks assessment and shortage analysis. The scope of disruption risks is limited in the paper and includes non-systematic risks (i.e., micro risks). Based on approximation data, the author has constructed a methodology for the identification of products, which face a higher risk to have shortage and a probability of getting it. The case analysis of Lithuania for drug shortage in the period 2018 is presented.
\end{abstract}

Keywords: Disruption, Drug shortage, Metrics, Supply.

\section{Introduction}

In a functioning health system, equitable access to essential drugs and medicines should be ensured. If this condition is not followed, shortage appears. AHPSR's (The Alliance for Health Policy and Systems Research) observation states that systemic disruptions and their impacts have hardly been studied. The main supply disruptions are identified and presented as follows:

1) The lack of information among distribution chain partners.

2) The unavailability of drugs and delays in the distribution channel.

3) The multiplicity of distribution channel parties and the difficulty of identifying responsible one or negative attitude of providers.

4) Deficiencies in planning and communication.

5) Under-distributing system improvement, difficulties in meeting expenses, and frozen working capital and operational costs for over-distribution in the chain.

The author has identified the main risks under delays, forecast and inventory categories, and has also specified methods applicable for risks analysis. A methodology has been suggested, which aims to categorize products based on the probability of risk occurrence and, to identify the result after a disruption.

\section{Literature Review}

*Lecturer and Researcher, Vilnius University, Lithuania. 
There are many risks in the supply chain when unexpected events happen and the smooth flow of drugs from producers to patients might be disrupted. The topic of risk assessment is widely discussed in various study fields, such as economics and strategic and international management (Alruthia et al. 2018, Tang and Musa 2011).

Lavastre et al. (2012) emphasised three elements to define a risk: the occurrence of lost (number of lost events), its importance (size of lost) and its probability of appearance (uncertainty of lost events). The probability of loss and the significance of it, could be researched from two different perspectives, from enterprise position and from a patient position.

Literature separates macro risks and micro risks. Some examples of macro risks are mentioned. Klibi et al. (2010) analysed disruption sources and discussed environmental events. Blome and Schoenherr (2011) pointed out that the supply chain became more complex and such resulted in higher supply system vulnerability. Juttner (2005) highlighted security and Wakolbinger and Cruz (2011) promoted risk-sharing contracts. They state that in recent years the macro disruptions have been caused by fuel protests, by terrorist attacks, which widely affected system vulnerability. Tang (2006) stated that due to uncertainties in producing unique flu vaccine formula, also unstable market demand, and price pressure from the USA government caused shortages, as many flu vaccine producers left the market. The reducing number of flu vaccine producers left Americans at risk (Tang 2006). Hendricks and Singhal (2005) explained that focus on efficiency in recent years (i.e., lowering costs) caused the increase of supply disruptions, for which management companies did not place enough the effort.

The author has analysed research papers and provided three main categories of risks, which all are shown in Table 1.

According to Tang and Tomlin (2016), risks measurement has two dimensions, the probability of occurrence and the effect of fault. Baghalian et al. (2013) separated risks into two categories, systematic risks related to environmental factors, not controlled by companies, and non-systematic risks, related to factors controlled by the enterprise, i.e., internal facility disruptions. Sadghiani et al. (2015) noticed that the mitigation of non-systematic risks could increase competitive advantage. Simchi-Levi et al. (2014) highlighted frequent non-systematic disruptions: unreliable supplier, inaccurate forecast, unreliable transport system, and stated that historical data could help to quantify the level of risk. Scholten et al. (2014) explained that building the resilient supply chain could lead to avoiding exposure (vulnerability) of risks. Juttner et al. (2003) presented the broader picture and stressed the lack of ownership for highly integrated systems, where companies face the risks of product obsolescence, the lack of responsiveness and this causes shortages. 
Table 1. List of Micro Risks and Research Interest

\begin{tabular}{|c|c|c|}
\hline Main Risks & Drivers of Micro Risks & Authors \\
\hline \multirow[t]{6}{*}{ Delays } & Accidents & Christopher and Peck 2004 \\
\hline & Equipment and labour issues & Kleindorfer and Saad 2005 \\
\hline & Operational performance & $\begin{array}{c}\text { Hendricks and Singhal 2005, Lio } \\
\text { and Liu } 2019\end{array}$ \\
\hline & Unreliable transport system & Christopher and Peck 2004 \\
\hline & Packing material & Atilgan and McCullen 2007 \\
\hline & Unreliable supplier & Chopra et al. 2007 \\
\hline \multirow[t]{3}{*}{ Forecast } & Lack of visibility in the supply chain & Heckmann et al. 2015 \\
\hline & Inaccurate forecast & Chopra and Sodhi 2014 \\
\hline & $\begin{array}{c}\text { Under-estimated demand due to shortage } \\
\text { cases }\end{array}$ & Tummala and Schoenherr 2011 \\
\hline \multirow[t]{6}{*}{ Inventory } & Product obsolescence & Tummala and Schoenherr 2011 \\
\hline & Damages during the supply process & Sawik 2013 \\
\hline & Human error & Atilgan and McCullen 2007 \\
\hline & Mismatch of physical and system stock & Atilgan and McCullen 2007 \\
\hline & Quality problems & $\begin{array}{l}\text { Christopher and Peck 2004, Sawik } \\
2013\end{array}$ \\
\hline & Coordination & $\begin{array}{c}\text { Wagner and Bode 2008, Schmitt } \\
\text { and Singh 2009, Zhao and Zhu } \\
2018\end{array}$ \\
\hline
\end{tabular}

Methods Applicable for Risks Analysis

In the supply process, a supplier (or resource) is upstream or downstream. When a supplier is upstream, it supplies quantity in full and on time, but downstream the order could not be supplied. Bode and Wagner (2015) use standard accident theory to explain downstream supply chain disruptions. In the literature, the supply-disruption process is analysed from a single supplier side perspective.

Two different categories of models are provided by the authors, yielduncertainty models and supply-disruption models. The first type of models differs from the second type of models. There is no supply uncertainty in yielduncertainty models. Most of the models focus on single-period cases, and only a few of them are dedicated to multi-period. The ability of a company to adjust capacity is the multi-period setting. The central aspect of yield-uncertainty models is that company chooses inventory quantity, and this decision directly influences capability during a contingency case. Enterprises managing risks, usually overlook this aspect over products supply chains.

Another type of models is supply-disruption models. Supply-disruption models differ from demand-uncertainty models. In contrast, yield-uncertainty 
refers to a single form of supply uncertainty in cases when the quantity produced or inbounded is different from the quantity ordered. Papers presenting optimal strategy are dealing with supply disruption, which is opposite to demand uncertainty, dealing with random quantity and happening more frequently (for every order) but less severe than supply uncertainty (Snyder and Shen 2006). In most of the models, supply disruption means the inability to provide any products (Snyder et al. 2016). Snyder et al. (2006) delivered a model which focuses on order supply-disruptions in the downstream supply chain. Serel (2008) presented a model for upstream supply chain, which is a single period with one supplier facing supply disruption. Tomlin (2006) delivered a study, focusing on the optimal ordering policy. Furthermore, Hou et al. (2010) presented the optimal ordering policy under intermittent supply disruption.

There are three models with supply uncertainty with different probability and various periods versions single, or multiple. All models prove optimal ordering policy. The first model assumes the probability that a supplier delivers an order. This probability is random. The second and third models consider yield uncertainty, where demand itself is stochastic but has continuous distribution. There are also models, which cover both demand (DU) and supply (SU) uncertainties. In those models one SU or DU respectively is deterministic, for example, when supply is uncertain, demand is deterministic, and vice-versa. The result of these models is the highlight of different strategies that are appropriated. To compare demand uncertainty and supply uncertainty authors define the level of uncertainty in the percentage of appeared uncertainty cases. For risk analysis, three primary methods are used:

1. Probability analysis.

2. Shortage causes tree analysis and causal modelling.

3. System vulnerability analysis.

Below is a description of these methods:

1. Probability analysis - processes may have the same probability of being disrupted, but the disruption length could be different. Under different probability and severity are modelled scenarios of disruptions (Deleris and Erhun 2005). Some studies try to determine the probability of lost sales volume but not the size of lost sales; the model scenarios of multi-product or multiple supply sources. Other authors just delivered case analysis. For example, Jaberidoost et al. (2015) have used probability analysis to analyse regulatory risks in Iran. The above-mentioned authors classified risks into financial management risks, sales management, operation management, quality management and supply \& suppliers issues and others. For each type of risk, they estimated the probability to identify top risks. Afterwards, they constrained probability-hazard chart. The probability component is also included in economic models. One of such models is Shavell model, where probability is treated as a disruption during a time frame, as a function of investments to mitigate the probability of disruption or resulting 
losses. The Shavell model is the most straightforward useful framework in the area of risk analysis, leading to more effective risk mitigation expenditures and reduced accident rates (Kleindorfer and Saad 2005).

2. Shortage causes tree analysis (FTA) and causal modelling - it is partly covered by the ISO 31000 Risk Management Standard (Bharathy and McShane 2014).

The first technique is the fault-tree analysis (FTA). The fault-tree is a graphical representation that shows how shortage event could occur in various ways by systematical identification of the probable sequence of events.

In the literature, a lot of quantitative models are delivered (Ho et al. 2015). Tang (2006) revised around 200 articles, which rely on quantitative models. Halpern and Pearl offered the precise modelling of many meaningful causal relationships (Eiter and Lukasiewicz 2012). Eiter and Lukasiewicz (2012) have delivered causal models with week and actual causes and offered the reduction of weak causes. More than 50 internal and environmental characteristics are used for these analyses and prove cause-and-effect hypothesis raised by authors. By using descriptive statistics, analysis is presented, and regression results are reported, often for many potential predictor variables.

There is also a linear regression analysis for these types of cases. In these models, regression results are often transmuted directly into causal claims (e.g., identified risk characteristics leading to such consequences) or causal implications (e.g., focusing on the changes of identified risk characteristics aiming to improve overall outcome). At the end of the synthesis application, the result of formed linear regression models with limited evidence of causal relationship is provided. Statistical tests of variables and interactions are not adjusted for more proximate characteristics, such as communication, which are added in higher-level models. A hypothesis is usually supported by the statistical significance of the interaction among partners in the supply chain.

Causal effects in regression models also can be analysed from the hierarchical (or sequential) approach. The hierarchical (or sequential) approach involves comparisons across a series of theory-informed regression models in which independent variables are sequentially added in small subsets. The ordering of these models is critical, as all variables are statistically adjusted for all other variables in the same model and previous models, but not for variables in subsequent models. One critical hypothesis tested in the model, was the interaction between inventory level and drug shortage (Chabner 2011, De Weerdt et al. 2015, Ridley et al. 2016).

Another option is to apply the elaboration method, developed in the 1940s, for causal modelling. This method begins with the specification of a hypothesised causal relationship between a pair of variables (referred to as the focal relationship) and employs a series of regression models to rule out alternative explanations. One such analysis provided evidence in support of the hypothesised mediating role of forecasting on the focal relationship between supply chain parties. 
One more complex option includes path analysis, structural equation modelling, and graphical models. These assume causal links and the strength of the links for the correct representation of reality. All these sophisticated tools are used to support the development and comparison of explanatory regression models under the guidance of an explicit theoretical framework. They can provide useful directions or standardised approaches, but they do not represent the process of causality research. Researchers make a comparison of regression models and evaluation of theory-driven hypotheses in many ways, and provide compelling arguments involving carefully developed evidence and propose solutions for implications, which bring outcome if theory-based regression analysis is applied correctly.

Two-stage least square (TSLS) is widely used in econometrics to estimate parameters in systems of linear equations. One of the known models is called the Rubin causal model, developed in 1974. TSLS could be used to estimate the average causal effect of a variable, such as a drug dosage. The average causal effect is different from the absence of treatment. It is built by giving the assumptions for probability together with the interval required to respond to appropriately defined causality (Angrist and Imbens 1995).

Sensitivity analysis is an essential tool for the evaluation of mathematical models (Enyinda et al. 2010). In practice, the sensitivity analysis is carried out by changing the parameters and getting an overview of the most sensitive components of the model. The sensitivity analysis is carried out at two or more levels of parameter changes. Sensitivity analysis can be used for the identification of model uncertainties and for determining potential areas for further analysis (Lehr et al. 1994).

3. For system vulnerability analysis, multiple criteria evaluation methods are used. Different types of methodologies have been proposed for system vulnerability risks assessment analysis. Multiple attribute decision-making problems are encountered, where a less risky alternative is chosen based on the set of risks evaluated (Samvedi et al. 2013).

Authors consider an integrated approach, where they identified and a risk index classification structure to:

- Ensure that the decision-makers follow a 'rational' system behaviour utility theory (i.e., the strategy representing the utility), value functions (i.e., determining the best and the worst values), and distance to the ideal point (i.e., index representing the closeness of a specified measure to the ideal solution).

- Build the risk evaluation indexes system.

- Find the preferred solution.

Multiple criteria evaluation methods are used to figure out which alternative has received the highest score. Numerous methods have been developed for the multiple attribute analysis of drug supply problems. Wide known methods used for 
multiple attribute decision making in pharmaceutical supply chain risks assessment are, Analytic Hierarchy Process (AHP) (Ilbahar et al. 2018), Recommender Systems (RS), Simple Additive Weighting (SAW) (Jaberidoost et al. 2015), Analytic Network Process (ANP) (Yüksel and Dagdeviren 2007), Fuzzy Analytic Network Process (F-ANP) (Moeinzadeh and Hajfathaliha 2009), Multi-Criteria Optimisation and Compromise Solution (VIKOR) (Sanayei et al. 2009), Fuzzy Multi-Criteria Optimisation and Compromise Solution (F-VIKOR) (Moeinzadeh and Hajfathaliha, 2009), and others.

One type of system vulnerability analysis is the analysis of a network's reliability. Network reliability models, sometimes, consider the cost of constructing a network. The mathematical models can be used to analyse the system's reliability increase. To measure the reliability of the network, some researchers have developed models to describe its elements and activities.

Traditional models for the strategic design of network focus on cost-efficiency, not considering disruptions of inventories or supply. Just-In-Time models are assuming that every element in the network is always performing as planned, which in practice not always happens. Also, for system vulnerability analysis could be the models representing supply chain activities coordination. The summary of all the above-presented methods is shown in Figure 1.

Figure 1. The Summary of Methods Applicable for Risks Assessment Research

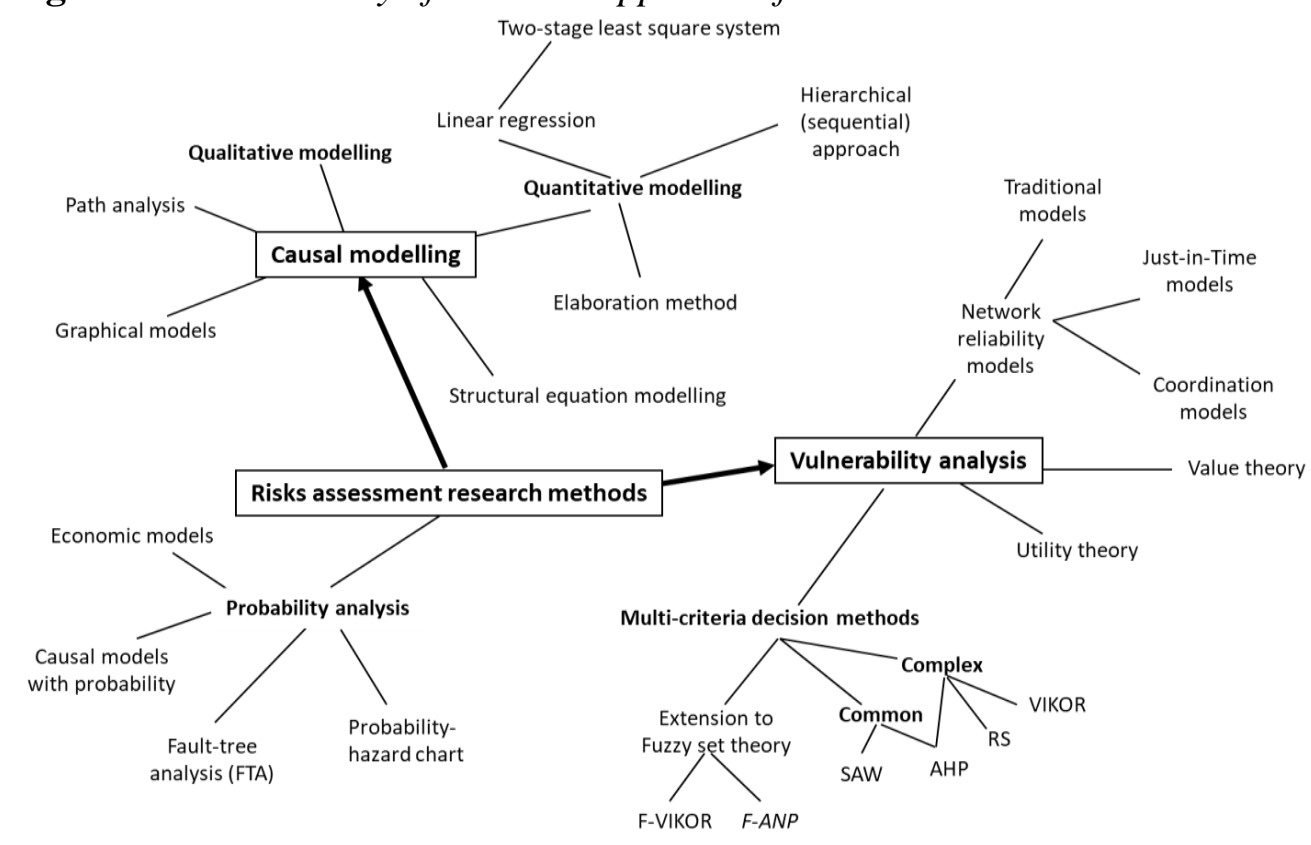

Source: Author.

\section{Methodology}

The measurement of disruption effects involves a sequence of steps as follows: 
1. Risk assessment of considered products.

2. Detection of outliers and evaluation of data points.

3. An economic evaluation of lost sales.

4. The mean absolute percentage error (MAPE) indication.

Firstly, the author suggests a risk assessment method that is based on the variability of products demand. The riskiness of a considered product $(i)$ is measured by a beta $\left(\beta_{i}\right)$. It is calculated as a ratio of sales standard deviations of two products from the same category. The product with the least sales standard deviation $\left(S t D_{l r}\right)$ in the whole category (and with the least out of stocks) goes as a nominator, while a standard deviation of a considered item goes for the denominator $\left(S t D_{i}\right)$.

$$
\beta_{i}=\frac{S t D_{\mathbb{V}}}{S t D_{i}}
$$

It means that the medical products with low sales variability, serve as benchmarks in the categories they belong to.

The whole sample of more than 100 products, selected for testing, was divided into three categories based on the values of their betas: the highest, moderate, and low riskiness (Table 2).

Out-of-stocks were calculated for each level of riskiness, as an average percentage rate for the whole category that measures time without a product. Besides, the stock-out probability for each category level was measured as well. It indicates the percentage of products that suffer from stock-outs in the category.

Table 2. The Levels of Demand Variability

\begin{tabular}{|c|l|c|c|}
\hline Values of $\beta_{i}$ & \multicolumn{1}{|c|}{ Description } & Stock-out days, \% & $\begin{array}{c}\text { Stock-out } \\
\text { probability }\end{array}$ \\
\hline $2=<$ & The highest riskiness & tbd & tbd \\
\hline $1.50-1.99$ & Moderate riskiness & tbd & tbd \\
\hline $1.00-1.49$ & Low riskiness & tbd & tbd \\
\hline
\end{tabular}

Source: Author.

This method implies the satisfaction of an assumption of the normal distribution for each product sales (Figure 2).

At the second step, in order to estimate the disruption effect, it is necessary to get the sales pattern and gather data cleaning method. By using cleaned sales pattern, it will be possible to determine the effect size. In the study, further on lost sales estimation is generated by using cleaned data.

In general, time series method is used to forecast future demand by estimating patterns in the past, because outliers (extreme points) often distort results downwards or upwards of analysis. Due to this, every sales analysis should begin with either a graphical or statistical identification of outliers. There are various outlier test methods, like Grubbs' test (1950), Rosner's test (2011), Barnett and Lewis (1994) test, Dixon test and David test. The author uses Grubbs' test Reallife data cleaning methods for outliers' adjustment. By using the outliers' 
adjustment method with a confidence level of $99 \%$ are identified outliers exceptions, where actual sales for specific period reach standard deviation boundaries. In such cases, sales are reduced to MIN and MAX acceptable sales boundaries.

Figure 2. The Normal Distribution and Shortage Risk

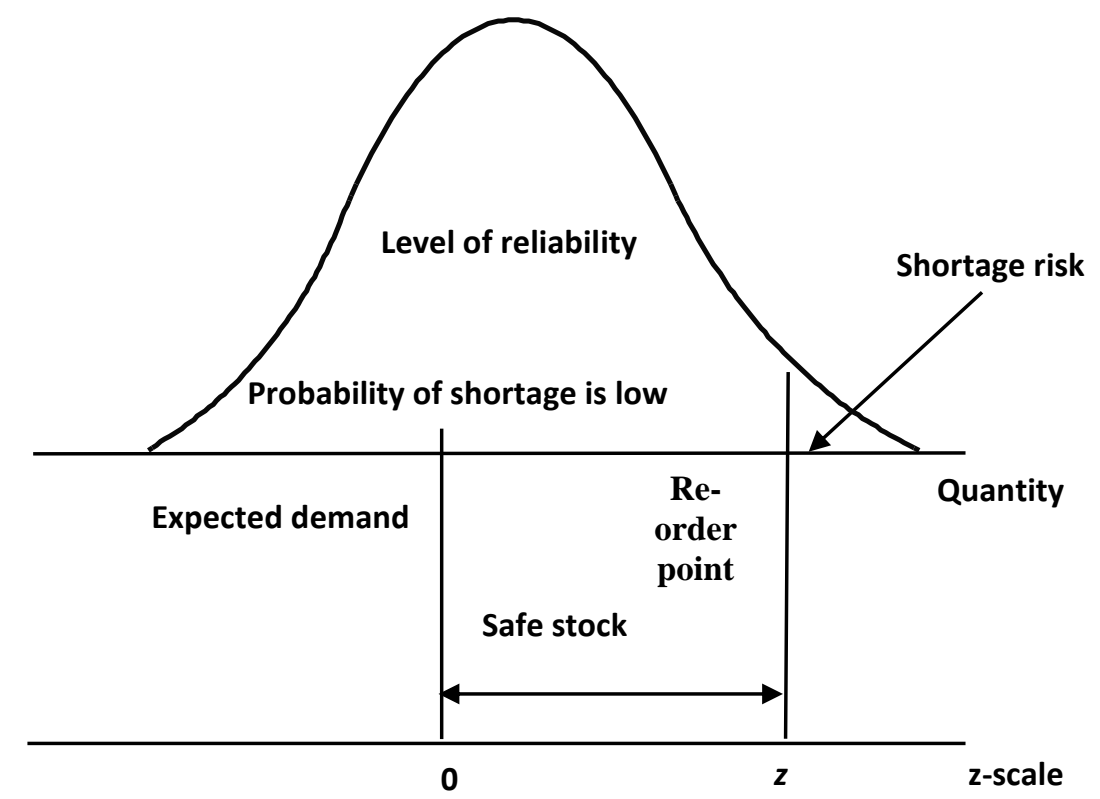

In general, such test detects outliers from the normal distribution. The result is a probability that indicates the core data of actual sales. The outliers' test method represents the difference of the mean of the sample and the most extreme data considering the standard deviation. The test can detect one outlier at a time, with different probabilities from a data set with an assumed normal distribution.

After historical data evaluation, further steps are taken to estimate average sales per sales day.

One of the critical issues is that pharmacies do not record during a shortage. Usually, average sales per sales day prediction help to protect the data from being downwards or upwards. If a product had sales less than average sales per day and had a shortage on that day, the difference is taken for prediction and vice versa. If a product had sales higher than average sales per day and had a shortage on that day, the effect of lost sales is not calculated. For new products, which have no six weeks sales date, category average sales level per product is given.

The problem is with multiple products, which have substitution. The increase in sales of product substitute is eliminated from pre-calculated lost sales. This step is given to adjust lost sales. Adjustment of sales also could be given for season sensitive categories. Finally, the calculated lost sales in quantity are converted to value. 
To estimate reached results for presented methodic MAPE indicator is used. MAPE calculation methodic is shown in Table 3. Herein, average MAPE ratio is a cumulative average calculated from the data available.

Table 3. MAPE Calculation Methodic

\begin{tabular}{|l|c|c|c|c|c|}
\hline Date & Monday & Tuesday & Wednesday & Thursday & Friday \\
\hline MAPE & 83.293 & 96.071 & 65.47 & 81.339 & 95.217 \\
\hline $\begin{array}{l}\text { Average } \\
\text { MAPE } \\
\text { Ratio }\end{array}$ & N/A & 89.682 & 81.61133 & 81.54325 & 84.278 \\
\hline
\end{tabular}

Source: Author.

MAPE is the indicator that presents the accuracy of methodic. It is calculated by benchmarking estimated lost sales with actual sales for products without shortage.

\section{Results}

The revision of disruption effects consists of several parts:

1. Risk assessment for products.

2. Detection of outliers and evaluation of data points.

3. An economic evaluation of lost sales.

4. MAPE indication.

The results are presented for each step that is performed in a particular sequence. In the risk assessment for products (1), the author classified products into two categories according to risk component. Then inside each category, a standard distribution analysis has been performed. This analysis presents products with demand variability component, low variability, middle variability and high variability. Figure 3 shows the results for products without shortage and Figure 4 the results for products with shortage (i.e., stock-out) cases during the period.

Figure 3. The Results for Products without Shortage

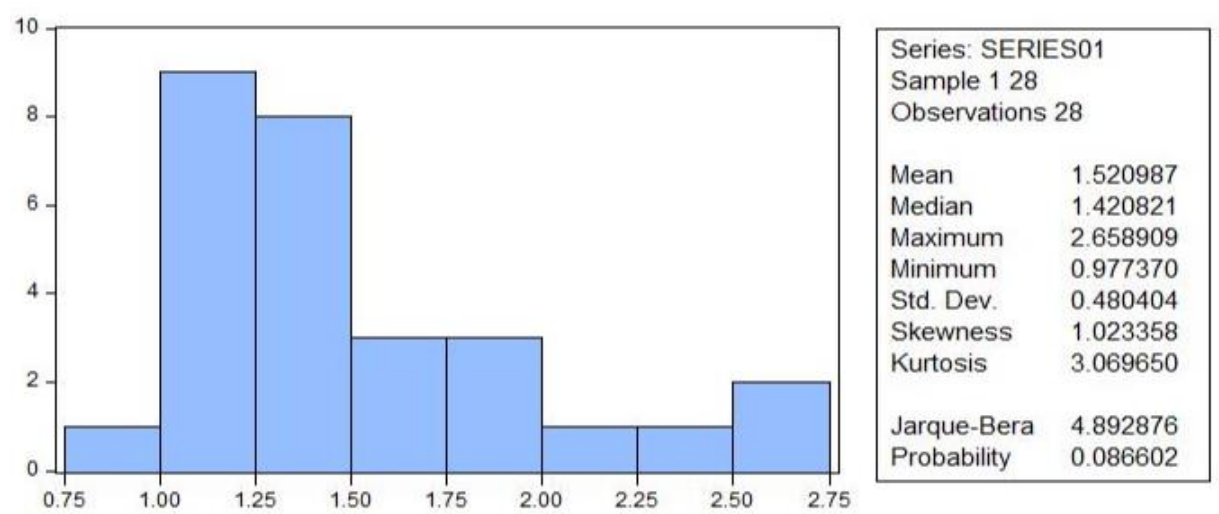

Source: Author by using EViewer Statistical Package. 
According to Figure 3, the normal distribution indicates the mean of betas; for low variability demand products is 0.977 , for middle variability demand products is 1.52 and for high variability demand products is 2.658 .

Figure 4. The Results for Products with Shortage



Source: Author by using EViewer Statistical Package.

According to Figure 4, the standard deviation for low variability demand products is 0.722 , for middle variability demand products is 1.76 and for high variability demand products is 2.9578 .

Even the normal distribution of products is overlapping; the mean and maximum for products with shortage are higher comparing those of products without shortage.

In the detection of outliers and evaluation of data points (2), the elimination of outliers helps to streamline sales data as for outlier case - sales points outside healthy distribution boundaries, sales data inside healthy distribution boundaries are taken. For example, the standard deviation for OOCULI $360 \mathrm{~mL}$ is 1.68 and Magnis+C is 2.68 .

Figure 5 shows the results for the detection of outliers, which is defined using the Grubbs' test method.

Two products from 15, had no outliers detected, such as Neuromed Sleep 15 tablets and VPLAB BCAA 8:1:1. Both fall under low or middle variability demand products.

Other products had one outlier - 5 products, of which Salicilis spirit 2\% 100 $\mathrm{mL}$ had negative $\mathrm{z}$-score outlier; 2 outliers were identified for seven products and three outliers - only for two products. 
Figure 5. The Results for Outliers' Detection by using Grubbs' Test Method

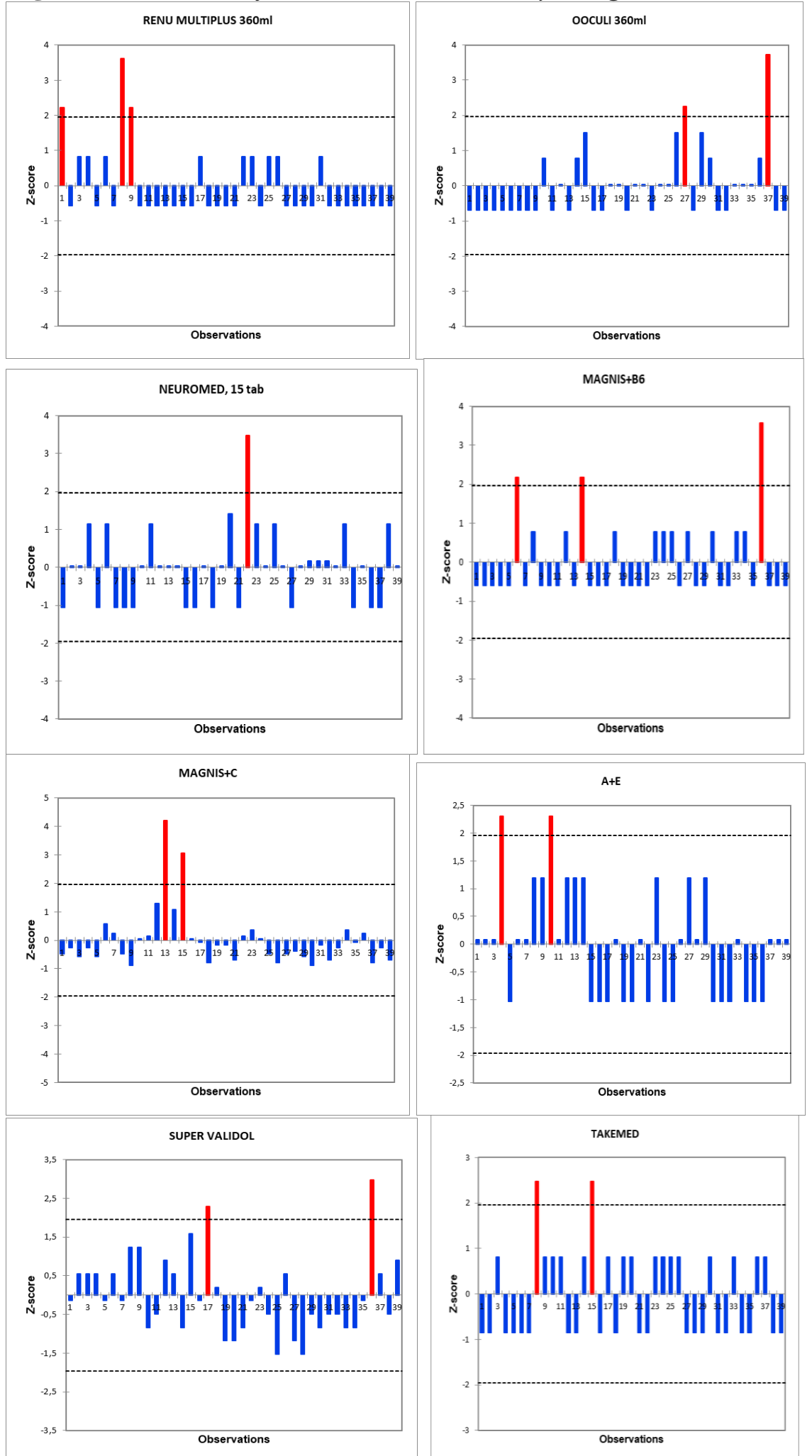

Source: Author by using the Leading Data Analysis and Statistical Solution for Microsoft Excel (XSTAT) Statistical Package. 
The value of standard deviation is between 0.549 and 5.933. As during the test 40 data points have been used, the delivered normality tests present acceptable results (Table 4).

Table 4. Results of Normality Test

\begin{tabular}{|l|l|l|l|l|}
\hline $\begin{array}{l}\text { Normality test } \\
\text { method }\end{array}$ & $\begin{array}{l}\text { Shapiro- } \\
\text { Wilk }\end{array}$ & $\begin{array}{l}\text { Anderson- } \\
\text { Darling }\end{array}$ & Lilliefors & Jarque-Bera \\
\hline Result & $<0.0001$ & $<0.0001$ & $<0.0001$ & 0.036 \\
\hline
\end{tabular}

Source: Author by using XSTAT Statistical Package.

The normal distribution of data is well represented for Peroxide, $3 \%$ and Salicylic spiritus, $100 \mathrm{~mL}$ and is shown in Figure 6. Both fall under low or middle variability demand products.

Figure 6. The Results of Normal Distribution

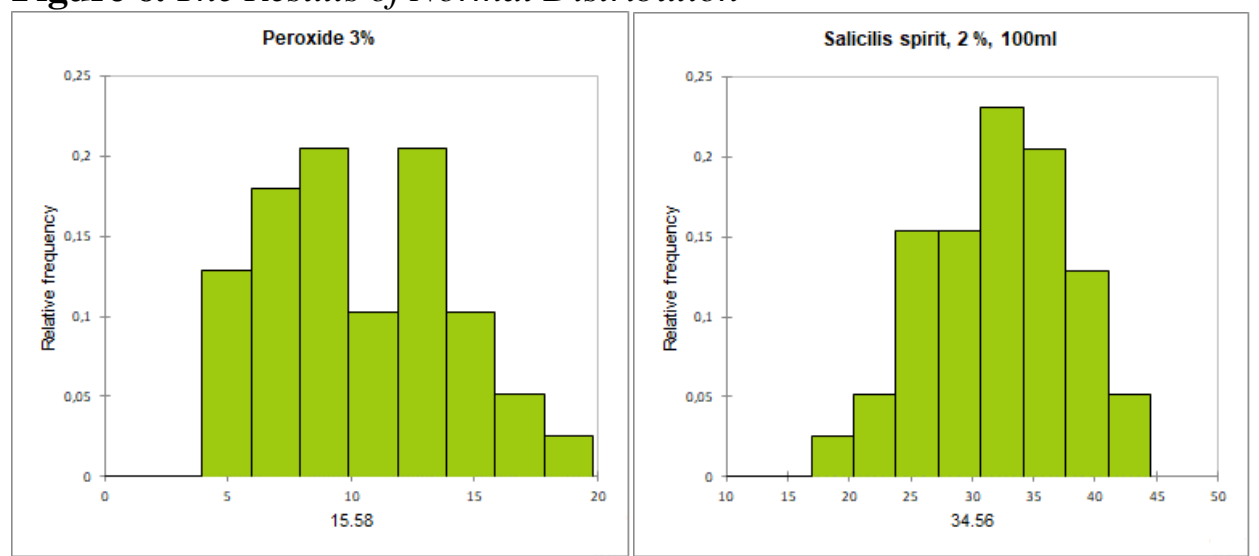

Source: Author by using XSTAT Statistical Package

In the economic evaluation of lost sales (3), for lost sales calculation, it has been used sales-stock ratio for each sales day and its average for the period; also, average stock for the period and the number of stock-out days. The average stock is multiplied from sales-stock ratio and the number of stock-out days to get the estimation of lost sales. After the estimated lost sales are benchmarked with sales per period to get the estimation of what is the level of lost sales from total sales. The estimation for products with shortage gives $32 \%$ lost sales ratio, whereas for products without shortage is just $4 \%$.

Finally, the author delivered the summary of results, where the number of stock-out days and probability to be in stock-out is identified.

Table 5. Summary of Results for Products

\begin{tabular}{|l|c|c|c|c|}
\hline Values of $\beta_{i}$ & $\begin{array}{c}\text { Stock-out } \\
\text { Days, \% }\end{array}$ & $\begin{array}{c}\text { Stock-out } \\
\text { Probability }\end{array}$ & $\begin{array}{c}\text { Sales-Stock } \\
\text { Ratio }\end{array}$ & $\begin{array}{c}\text { Lost Sales vs Total } \\
\text { Sales, \% }\end{array}$ \\
\hline $2=<$ & $23.35 \%$ & $69.23 \%$ & $4 \%$ & $41 \%$ \\
\hline $1.50-1.99$ & $15.77 \%$ & $50.00 \%$ & $6 \%$ & $34 \%$ \\
\hline $1.00-1.49$ & $8.10 \%$ & $34.62 \%$ & $10 \%$ & $30 \%$ \\
\hline
\end{tabular}

Source: Author. 
Products with a beta above 2, on average one week is on stock-out and probability to be on stock-out is $69.23 \%$; for products with a beta below 1.5 , on average less than three days are on stock-out and probability to be on stock-out is $34.62 \%$.

In MAPE indication, the given methodology was applied for products without shortage. The author has randomly selected the day of stock-out, calculated lost sales and compared them with actual sales on that day. The MAPE for this exercise was 0.3867 . The lower the MAPE is, the better the data performance is. The MAPE could be improved further with the application of another methodological approach.

\section{Discussion}

The author has suggested a methodology to classify products by risk and demand components. Products without shortage during month period were used for the benchmark with products, which had a shortage (i.e., stock-outs) in the defined period. Other researchers could improve the offered methodology in the area. The study has its limitations. So, future studies should expand this research application to such directions. Firstly, to the direction of risks assessment per categories analysis. Secondly, to the direction of stock-outs and demand forecast analysis. Thirdly, to the direction of analogue products selection in case of stockouts and finally, to the decision making tools construction.

\section{Conclusions}

There are many risks in the supply chain when unexpected events might disrupt the smooth flow of drugs from producers to patients. Risk assessment topic is widely discussed and analysed; there have been identified 15 non-systematic disruption risks and 24 methods that were developed for their assessment.

The method that falls into the category of probability analysis, has been suggested. The proposed methodology aims to distinct riskier products, to determine stock-outs probabilities for products being separated into different shortage related groups and, also, to help to the estimation of disruption risks effect.

In contrast to other methods, the one suggested by the author helps to identify the groups of products that are more vulnerable to disruption risks. It shows riskier products that have a higher out-of-stock probability.

The study reveals that higher sales-stock ratio matches with products of lower disruption risk, and vice versa.

\section{Acknowledgements}

This paper is prepared under research for the COST 15105 project 2019. 


\section{References}

Alruthia YS, Alwhaibi M, Alotaibi MF, Asiri SA, Alghamdi BM, Almuaythir GS, Alsharif WR, Alrasheed HH, Alswayeh YA, Alotaibi AJ, Almeshal M, Aldekhail SN, Alhusaini A, Alrashed SA, Alrumaih AM, Dahhas MA, Alghamdi MA, Aleheidib MS, Alhaidari MH, Alharbi JA, Almeshal M (2018) Drug shortages in Saudi Arabia: root causes and recommendations. Saudi Pharmaceutical Journal 26(7): 947-951.

Atilgan C, McCullen P (2007) Using "Quick Scan" at a medium-sized food company: a change management perspective. Developing Sustainable Collaborative Supply Chains 43(1): 215.

Angrist JD, Imbens GW (1995) Two-stage least squares estimation of average causal effects in models with variable treatment intensity. Journal of the American Statistical Association 90(430): 431-442.

Baghalian A, Rezapour S, Farahani RZ (2013) Robust supply chain network design with service level against disruptions and demand uncertainties: A real-life case. European Journal of Operational Research 227(1): 199-215.

Bharathy GK, McShane MK (2014) Applying a systems model to enterprise risk management. Engineering Management Journal 26(4): 38-46.

Blome C, Schoenherr T (2011) Supply chain risk management in financial crises - A multiple case-study approach. International Journal of Production Economics 134(1): 43-57.

Bode C, Wagner SM (2015) Structural drivers of upstream supply chain complexity and the frequency of supply chain disruptions. Journal of Operations Management 36(May): 215-228.

Chabner BA (2011) Drug shortages - a critical challenge for the generic-drug market. New England Journal of Medicine 365(23): 2147-2149.

Chopra S, Reinhardt G, Mohan U (2007) The importance of decoupling recurrent and disruption risks in a supply chain. Naval Research Logistics 54(5): 544-555.

Chopra S, Sodhi M (2014) Reducing the risk of supply chain disruptions. MIT Sloan Management Review 55(3): 72-80.

Christopher M, Peck H (2004) Building the resilient supply chain. The International Journal of Logistics Management 15(2): 1-14.

De Weerdt E, Simoens S, Hombroeckx L, Casteels M, Huys I (2015) Causes of drug shortages in the legal pharmaceutical framework. Regulatory Toxicology and Pharmacology 71(2): 251-258.

Deleris LA, Erhun F (2005) Risk management in supply networks using Monte-Carlo simulation, in ME Kuhl, NM Steiger, FB Armstrong, JA Joines (eds) Proceedings of the 2005 Winter Simulation Conference, 19-34. New York: IEEE.

Eiter T, Lukasiewicz T (2012) Causes and explanations in the structural-model approach: tractable cases. UAI, 146-153.

Enyinda CI, Mbah CH, Ogbuehi A (2010) An empirical analysis of risk mitigation in the pharmaceutical industry supply chain: a developing-country perspective. Thunderbird International Business Review 52(1): 45-54.

Heckmann I, Comes T, Nickel S (2015) A critical review on supply chain risk-definition, measure and modeling. Omega 52(Apr): 119-132.

Hendricks KB, Singhal VR (2005) An empirical analysis of the effect of supply chain disruptions on long-run stock price performance and equity risk of the firm. Production and Operations management 14(1): 35-52.

Ho W, Zheng T, Yildiz H, Talluri S (2015) Supply chain risk management: a literature review. International Journal of Production Research 53(16): 5031-5069. 
Hou J, Zeng AZ, Zhao L (2010) Coordination with a backup supplier through buy-back contract under supply disruption. Transportation Research Part E: Logistics and Transportation Review 46(6): 881-895.

Ilbahar E, Karaşan A, Cebi S, Kahraman C (2018) A novel approach to risk assessment for occupational health and safety using Pythagorean fuzzy AHP \& fuzzy inference system. Safety Science 103(Mar): 124-136.

Jaberidoost M, Olfat L, Hosseini A, Kebriaeezadeh A, Abdollahi M, Alaeddini M, Dinarvand R (2015) Pharmaceutical supply chain risk assessment in Iran using analytic hierarchy process (AHP) and simple additive weighting (SAW) methods. Journal of Pharmaceutical Policy and Practice 8(1): 19-28.

Juttner U (2005) Supply chain risk management: Understanding the business requirements from a practitioner perspective. The International Journal of Logistics Management 16(1): 120-141.

Juttner U, Peck H, Christopher M (2003) Supply chain risk management: outlining an agenda for future research. International Journal of Logistics: Research and Applications 6(4): 197-210.

Kleindorfer PR, Saad GH (2005) Managing disruption risks in supply chains. Production and Operations Management 14(1): 53-68.

Klibi W, Martel A, Guitouni A (2010) The design of robust value-creating supply chain networks: a critical review. European Journal of Operational Research 203(2): 283293.

Lavastre O, Gunasekaran A, Spalanzani A (2012) Supply chain risk management in French companies. Decision Support Systems 52(4): 828-838.

Lehr HA, Frei B, Arfors KE (1994) Vitamin C prevents cigarette smoke-induced leukocyte aggregation and adhesion to endothelium in vivo. Proceedings of the National Academy of Sciences, 91(16): 7688-7692.

Lio W, Liu B (2019) Shortage index and shortage time of uncertain production risk process. IEEE Transactions on Fuzzy Systems 99(Oct): 1-1.

Moeinzadeh P, Hajfathaliha A (2009) A combined fuzzy decision-making approach to supply chain risk assessment. International Scholarly and Scientific Research \& Innovation 3(12): 1631-1647.

Ridley DB, Bei X, Liebman EB (2016) No shot: US vaccine prices and shortages. Health Affairs 35(2): 235-241.

Sadghiani NS, Torabi SA, Sahebjamnia N (2015) Retail supply chain network design under operational and disruption risks. Transportation Research Part E: Logistics and Transportation Review 75(Mar): 95-114.

Samvedi A, Jain V, Chan FTS (2013) Quantifying risks in a supply chain through integration of fuzzy AHP and fuzzy TOPSIS. International Journal of Production Research 51(8): 2433-2442.

Sanayei A, Mousavi SF, Yazdankhah A (2009) Group decision making process for supplier selection with VIKOR under fuzzy environment. Expert Systems with Applications 37(1): 24-30.

Sawik T (2013) Integrated selection of suppliers and scheduling of customer orders in the presence of supply chain disruption risks. International Journal of Production Research 51(23-24): 7006-7022.

Schmitt AJ, Singh M (2009) Quantifying supply chain disruption risk using Monte Carlo and discrete-event simulation. In Proceedings of the 2009 Winter Simulation Conference, 1237-1248. New York, IEEE.

Scholten K, Sharkey SP, Fynes B (2014) Mitigation processes - antecedents for building supply chain resilience. Supply Chain Management: An International Journal 19(2): 211-228. 
Simchi-Levi D, Schmidt W, Wei Y (2014) From superstorms to factory fires: Managing unpredictable supply chain disruptions. Harvard Business Review 92(1-2): 96-101.

Serel DA (2008) Inventory and pricing decisions in a single-period problem involving risky supply. International Journal of Production Economics 116 (1): 115-128.

Snyder LV, Shen ZJM (2006) Supply and demand uncertainty in multi-echelon supply chains. Bethlehem, PA: Lehigh University, 20-32.

Snyder LV, Atan Z, Peng P, Rong Y, Schmitt AJ, Sinsoysal B (2016) OR/MS models for supply chain disruptions: a review. IEEE Transactions 48(2): 89-109.

Tang CS (2006) Robust strategies for mitigating supply chain disruptions. International Journal of Logistics: Research and Applications 9(1): 33-45.

Tang O, Musa N (2011) Identifying risk issues and research advancements in supply chain risk management. International Journal of Production Economics 133(1): 25-34.

Tang C, Tomlin B (2016) The power of flexibility for mitigating supply chain risks. In KS Pawar, H Rogers, A Potter, M Naim (eds) Developments in Logistics and Supply Chain Management, 80-89. London: Palgrave Macmillan.

Tomlin B (2006) On the value of mitigation and contingency strategies for managing supply chain disruption risks. Management Science 52(5): 639-657.

Tummala R, Schoenherr T (2011) Assessing and managing risks using the supply chain risk management process. Supply Chain Management: An International Journal 16(6): 474-483.

Wagner SM, Bode C (2008) An empirical examination of supply chain performance along several dimensions of risk. Journal of business logistics 29(1): 307-325.

Wakolbinger T, Cruz JM (2011) Supply chain disruption risk management through strategic information acquisition and sharing and risk-sharing contracts. International Journal of Production Research 49(13): 4063-4084.

Yüksel I, Dagdeviren M (2007) Using the analytic network process (ANP) in a SWOT analysis. Information Sciences 177(16): 3364-3382.

Zhao S, Zhu Q (2018) A risk-averse marketing strategy and its effect on coordination activities in a remanufacturing supply chain under market fluctuation. Journal of Cleaner Production 171(Jan): 1290-1299. 



\title{
How Patient Loyalty Affects Patient Satisfaction
}

\author{
By Burhanettin Uysal \& Mehmet Yorulmaz ${ }^{ \pm}$
}

\begin{abstract}
This study is a cross-sectional field study conducted to examine the effect of patient satisfaction on patient commitment based on the health institution which patients have recently visited. Two different scales were used in the study. The universe of the study consisted of patients who applied to hospitals in January 2019 and received inpatient health services to public hospitals, private hospitals, and university hospitals serving in the city of Konya. The questionnaires were applied by the researchers to the patients who were discharged from the hospital based on voluntariness by selecting the convenience sampling method. The data analysis was conducted with a $95 \%$ confidence level and 5\% tolerance in the SPSS 22.00 program. Non-parametric test techniques were used for the analysis. In accordance with the results of the correlation analysis, it was statistically found positive, low, and medium strength relations between general satisfaction and its sub-dimensions ( $p<0.01)$. According to the results of simple and multiple regression analysis, patient satisfaction affects patient commitment $(B=0.918$; p 0.01). The majority of patient commitment (54.1\%) is explained by patient satisfaction. In patient commitment, medical satisfaction makes a change by $29.2 \%$; interest and kindness a change by $32.2 \%$ and administrative satisfaction a change by 33.9\%. Patient satisfaction makes a change by $91.8 \%$ in patient commitment. Other variables are needed to explain the change of $8.2 \%$.
\end{abstract}

Keywords: Hospitals, Patient commitment, Patient satisfaction.

\section{Introduction}

Healthcare services are all medical activities carried out for the elimination of various factors damaging human health and protection of the society from the influence of these factors, treatment of patients, rehabilitation of those with reduced physical and spiritual abilities and angels (Resmi Gazete 1961: Law article 2). The main purpose of healthcare services is to produce various health services that appropriately meet the needs of patients (Öztürk 2014). Healthcare services structurally involve different characteristics from other service sectors. Health services differ from other service sectors because of a direct relationship with people's lives (Tüfekçi and Asığbulmuş 2016).

Patient satisfaction is one of the most important outputs of healthcare services. It is among the issues that are strongly emphasized within the service production process and quality studies. Based on the researches on patient satisfaction, factors such as the medical qualification level of health institution (quality of physicians, nurses, and such), and its physical structure, the cleaning of institution, the behaviors of the health personnel (communication, courtesy, and such), and the waiting period of patients, affect the satisfaction level of patients (Kılıç and Topuz 2016).

\footnotetext{
*Assistant Professor, Bilecik Seyh Edebali University, Turkey.

${ }^{ \pm}$Assistant Professor, Selcuk University, Turkey.
} 
The patient loyalty has gained importance for health institutions in parallel with some developments such as improving quality, improving patient satisfaction, and customer orientation in the health sector. Patient commitment can be defined as the preference of the same hospital when needed, characterizing the hospital's services positive and the hospital as a heartfelt hospital (Erdem et al. 2008).

\section{Literature Review}

\section{Patient Satisfaction}

Satisfaction is an evaluation and emotional response to the organization/ business in which a customer serves (Oliver 1997). Patient satisfaction is highly significant in terms of general structure, functioning, and outputs of health services. The patients who are satisfied with the health services provided by the hospitals meticulously adhere to their advice because they trust the physicians and other employees in the hospital. In case the patient is satisfied with the hospital and if s/he needs healthcare again, he will re-choose this hospital (Özer and Çakıl 2007).

Hospitals, like all businesses that maintain the purpose of customer satisfaction, also should focus on quality service and patient satisfaction in healthcare delivery. The patient who is satisfied with and re-prefers the same hospital, because of the satisfaction, he/she is expected to tell his/her surroundings (relatives, friends, etc.), and because of the probability of more people choosing the hospital will increase (Büber and Başer 2012).

Physical characteristics of hospitals that play a significant role in patient satisfaction involve specifications such as cleaning, heat, air-conditioning, lighting, noise, easy location, waiting rooms, parking, and appearance (Kavuncubaş1 and Yildirım 2012). When patients evaluate the health services, many of them assess by taking into consideration the attitudes and behaviors they encounter while providing the services, rather than the technical aspect of the services (Teke et al. 2007). It is known that some problems such as hospital infections and readmissions are necessary for the quality and safety programs of the hospitals. Hospital administration should take some precautions to reduce such negativities, because they can influence the satisfaction and commitment of the patients to the hospital (Hebert 2015). Factors affecting patient satisfaction are:

- The patient-related factors.

- The service provider-related factors.

- Organization-related factors (Özer and Çak1l 2007). 


\section{Patient-directed Factors}

Socio-demographic conditions of patients affect satisfaction in the delivery of healthcare services. However, it is seen that this situation is not consistent in all studies (Y1lmaz 2001).

\section{The Service Provider-related Factors}

In every step of the service delivery, the health employees in direct contact with the patients have a tremendous impact on patients' views and satisfaction about the services of the hospital (Korkmaz 2003). The kindness, compassion, interest, and understanding shown by the health employees and the way they present their knowledge and skills make the patient more relaxed and more harmonious and participatory in the treatment (Özer and Çak11 2007). In the event of a positive relationship between the patient and the practitioner, the patients fully comply with the recommendations of the physicians and do not interrupt the treatment offered (Kisa 2007).

When people get sick, they tend to feel more vulnerable and under less control than ever before. For that reason, respect and empathy are crucial for establishing a healthy relationship with patients. Active listening and demonstrating that the patients' concerns recognized is a fundamental component of promoting information sharing and effective patient-physician communication (Teutsch 2003).

\section{Organization-related Factors}

Recently, because of the developments in the health sector, some concepts such as respect, trust, rights, and privacy during service delivery in health institutions have begun to emerge more prominently (Özata and Özer 2017). In all healthcare service processes, the requirement to ensure the privacy of the patient is specifying Hospital Standards and evaluation criteria in the Health Quality Standards. According to these standards, patient consent should be obtained in case of participation in research and experimental studies or the use of data, information, and materials belonging to the patient for any reason. In this view, patient confidentiality should be taken care of (Uysal and Yorulmaz 2018).

Being informed and guided by the institution is of great importance. For patients:

- Possible causes and the course of the disease.

- By whom, where and how to perform the medical intervention and the estimated time.

- Other diagnostic and therapeutic options and the benefits and risks of these options and the possible effects of them on the patients' health. 
Prospective complications:

- Potential benefits and risks that may arise in case of rejection.

- Important properties of the drugs to be used.

- Lifestyle recommendations that are critical to health.

- When it is necessary, information is given on how to reach medical aid in the same subject (Resmi Gazete 1987: Law article 15).

The physical conditions are an important resource in terms of providing clues that a client looks for before buying the service (Esatoğlu 1997). Boshoff and Gray (2004) found that features in the external appearance such as cleanliness, elegance, the decor, and rooms of the hospital, employees' clothing and appearance play an essential role in patient satisfaction. On the other hand, another factor affecting satisfaction in the delivery of healthcare services is the disruptions and difficulties in bureaucratic procedures. The time losses in the bureaucracy and the waiting in the service process can affect patient satisfaction, negatively. During patient admission and discharge procedures in hospitals, some problems can arise due to prolonged waiting of patients and their relatives. Hence, the fact that hospitals keep these conditions at a good level can affect patient satisfaction positively. The time loss that may happen during patient admission and discharge procedures may cause complaints of patients and relatives (Öz 2004).

During the provision of health services, the expectations of the patients/clients are rather important. Public or private health institutions, providing outpatient or inpatient treatment services, perform activities related to components of service by evaluating health services and patient expectations (Öztürk 2014).

\section{Patient Commitment}

The concept of patient commitment is related to hospital services and is considered in terms of general management and managers (Erdem et al. 2008). Commitment is defined as the intention and request of the participant to maintain the relationship (MacMillan et al. 2005). As a result of high-quality service provided by the hospitals, patients will always increase their commitment to the hospital that presents an appropriate treatment. Therefore, service quality and patient satisfaction are the prerequisites for loyalty (Kandampully and $\mathrm{Hu} 2007$ ).

A patient satisfied with the health services becomes a loyal customer of the hospital and prefers the same hospital unless there is a negative situation (Gülmez 2005). The commitment to the hospital of patients who trust the hospital increases. In this context, it can be said that satisfaction is a significant factor in influencing hospital preference (Tüfekçi and Asığbulmuş 2016).

The advancement of the service quality provided in healthcare institutions positively affects the satisfaction of the patients and relates to the re-preferring and the recommendation of the health institution (Ramez 2012). The patients satisfied with the healthcare services of the hospital recommend the hospital to other people, because they trust the physicians and other employees in the hospital (Özer and Çakıl 2007). 
The patient left the hospital dissatisfied is not expected to prefer the same institution in later times (Gülmez 2005). The patient accurately uninformed about the treatment may experience negative emotions such as fear, worry. As a consequence, the process of the treatment may be affected negatively. This situation can consistently affect both patient satisfaction and hospital choice in a negative way (Tüfekçi and Asığbulmuş 2016).

The principle of respect for patient autonomy in healthcare services is accepted as a fundamental principle. Following the patient given an opportunity of own autonomous choice and action listening to the patient carefully, answering questions, and informing about the disease properly should be paid attention (Aslan et al. 2008).

The commitment model developed by Allen and Meyer (1990) involves emotional, continuance, and normative commitment.

An individuals' participation in the organization and the mental connection with the organization is expressed as emotional commitment. The emotional commitment is that patients are attached to hospitals with a sense of gratitude for treating themselves (Derin and Demirel 2011).

Since leavings' cost the organization is high, the continuation of the organization membership is expressed as continuance commitment. With continuance commitment, the individual cannot leave the organization, even if s/he wants, for leaving the organization will be costly and will have difficulties (Ceylan et al. 2005).

Normative commitment is expressed as a perceived obligation to remain in the organization (Allen and Meyer 1996). Patients, who want to regain healthy situations according to the examination and treatment processes within the hospital they prefer, want to take the hospital service as obligatory, during the treatment.

\section{Materials and Methods}

This study is a cross-sectional field study conducted to examine the effect of patient satisfaction on patient commitment based on the health institution where visited recently.

In this study were used two scales. The first is the scale of patient satisfaction and the second is the scale of patient commitment. Both scales were improved by Erdem et al. (2008). Cronbach's alpha was found high as 0.90 for patient satisfaction and 0.92 for patient commitment. The scale of patient satisfaction consisted of 15 expressions and three dimensions. The scale of patient commitment consisted of 11 expressions and one dimension.

The hospitals were divided into three as public hospitals, private hospitals, and university hospitals. According to the socio-demographic data of the patients, comparisons were made both on the general scale and its' sub-dimensions. The study's' universe consisted of patients admitting to hospitals in January 2019 and receiving inpatient healthcare services in public hospitals, private hospitals, and university hospitals that provide services in the city of Konya. The questionnaires were applied to the patients discharging from the hospital by selecting the 
convenience sampling method, according to volunteering. SPSS (Statistical Package for the Social Sciences) 22.0 package program was used to analyze the data. The loss data and extreme values were checked in the SPSS. The normality test was performed to determine the test technique to be used in comparative analysis. For not normally distributed was used Mann-Whitney U test for the comparison between paired groups and Kruskal-Wallis $\mathrm{H}$ test for comparison of more than two groups. The Bonferroni correction (with the Mann-Whitney U test) applied to find the source of the difference between groups. The Spearman Correlation Test applied to determine the relationship between the scales and the sub-dimensions. Simple linear regression analysis was conducted to determine the effect of patient satisfaction on patient commitment. On the other hand, multiple regression analysis was done by using the Enter method to reveal the effect of independent variables (satisfaction with medical and administrative services and interest and courtesy) on the dependent variable (patient commitment).

\section{Results}

\section{Socio-Demographic Characteristics of the Participants}

According to the information in Table $1,80 \%$ of the participants are under the age of 45 and about $2 / 3$ of them are female. According to marital status, nearly $40 \%$ of the participants are single. Looking at the education level of the participants, the highest rate is in the bachelor group (42.1\%). The lowest rate is $(3.9 \%)$ in the master's degree group. The ratio of primary and middle school graduates is over $1 / 3$. When seen in the last visit of the participants to the hospital, the rate of those who go to the university hospital is higher than the others but very close to the public hospital. According to the average monthly income of the participants, those who make up to 1.600 TL have the lowest.

Table 1. Socio-Demographic Characteristics of the Participants $(N=280)$

\begin{tabular}{|l|c|c|l|c|c|}
\hline Gender & $\boldsymbol{N}$ & $\mathbf{\%}$ & Education Level & $\boldsymbol{N}$ & $\mathbf{\%}$ \\
\hline Male & 95 & 33.9 & Primary school & 73 & 26.1 \\
\hline Female & 185 & 66.1 & Middle school & 28 & 10.0 \\
\hline Age Interval & & & High-school & 50 & 17.9 \\
\hline $18-24$ & 61 & 21.8 & Bachelor's & 118 & 42.1 \\
\hline $25-31$ & 50 & 17.9 & Master's degree & 11 & 3.9 \\
\hline $32-38$ & 58 & 20.7 & Marital Status & & \\
\hline $39-45$ & 55 & 19.6 & Married & 169 & 60.4 \\
\hline 46 and older & 56 & 20.0 & Single & 111 & 39.6 \\
\hline Monthly Income & & & Recently Visited Hospital & & \\
\hline 0-1600 TL & 21 & 7.5 & Public hospital & 101 & 36.1 \\
\hline 1601-2500 TL & 82 & 29.3 & Private hospital & 73 & 26.1 \\
\hline 2501-3500 TL & 89 & 31.8 & University hospital & 106 & 37.9 \\
\hline 3501-4500 TL & 44 & 15.7 & Total & $\mathbf{2 8 0}$ & $\mathbf{1 0 0 \%}$ \\
\hline 4500 TL and above & 44 & 15.7 & & & \\
\hline
\end{tabular}


$\underline{\text { Reliability analysis }}$

The scales used in the study are the scale of patient satisfaction and patient commitment. Patient satisfaction has three sub-dimensions that are medical satisfaction, interest-courtesy, and administrative satisfaction. There is no subdimension of patient commitment (Erdem et al. 2008).

Table 2. Reliability Analysis

\begin{tabular}{|l|c|c|c|}
\hline Scales and Sub-Dimensions & $\begin{array}{c}\text { Number } \\
\text { of Items }\end{array}$ & $\begin{array}{c}\text { Cronbach's } \\
\text { alpha }\end{array}$ & Erdem et al. \\
\hline Patient Satisfaction & 14 & 0.799 & 0.90 \\
\hline Medical Satisfaction & 3 & 0.520 & 0.72 \\
\hline Interest and Courtesy & 5 & 0.616 & 0.65 \\
\hline Administrative Satisfaction & 6 & 0.761 & 0.82 \\
\hline Patient Commitment & 11 & 0.911 & 0.92 \\
\hline
\end{tabular}

The coefficients of Cronbach's alpha $(\alpha)$ are shown in Table 2, according to the reliability analysis of patient commitment and overall satisfaction scales and sub-dimensions. The values of Cronbach's alpha $(\alpha)$ are shown in Table 2, according to the reliability analysis of patient commitment and overall satisfaction scales and sub-dimensions. According to this information, Cronbach's $\alpha$ coefficient of patient commitment is the highest, and the lowest level of medical satisfaction.

Correlation analysis

Correlation analysis is a statistical analysis technique used to determine whether the relationship between scale and sub-dimensions by making binary comparisons and the direction (+/-) in which the relationship/relationships if there is a relationship, or used in the evaluation of the hypotheses generated in the research. Otherwise, to determine the correlation technique being used was investigated the normality of the distribution.

The results of the correlation analysis between the scales and the subdimensions are shown in Table 3.

In the correlation analysis, the strength of the relationship between the scale and sub-dimensions is showed: very low between 0-20; 21-40 low; 41-60 mid; high between 61-80 and very high between 81-100 (Karagöz 2016; Y1ldırımKaptanoğlu and İşçi 2013).

According to the results of Spearman Correlation Analysis in Table 3, there was a statistically positive, high, and significant relationship between overall patient satisfaction and patient commitment $(r=0.686$; $p<0.01)$. 
Table 3. Spearman Correlation Test

\begin{tabular}{|l|c|c|c|c|c|c|}
\hline Scales and Sub-Dimensions (N=280) & A & B & C & D & E \\
\hline \multirow{2}{*}{ Patient Satisfaction $(A)$} & $\mathrm{r}$ & 1.000 & $0.672^{* *}$ & $0.686^{* *}$ & $0.863^{* *}$ & $0.686^{* *}$ \\
\cline { 2 - 7 } & $\mathrm{p}$ & & 0.000 & 0.000 & 0.000 & 0.000 \\
\hline \multirow{2}{*}{ Interest and Courtesy $(C)$} & $\mathrm{r}$ & & 1.000 & $0.352^{* *}$ & $0.427^{* *}$ & $0.480^{* *}$ \\
\hline & $\mathrm{p}$ & & & 0.000 & 0.000 & 0.000 \\
\hline \multirow{2}{*}{ Administrative Satisfaction $(D)$} & $\mathrm{r}$ & & & 1.000 & $0.401^{* *}$ & $0.573^{* *}$ \\
\cline { 2 - 7 } & $\mathrm{p}$ & & & & 0.000 & 0.000 \\
\hline \multirow{2}{*}{ Patient Commitment $(E)$} & $\mathrm{r}$ & & & & 1.000 & $0.556^{* *}$ \\
\cline { 2 - 7 } & $\mathrm{p}$ & & & & & 0.000 \\
\hline & $\mathrm{r}$ & & & & & 1.000 \\
\hline
\end{tabular}

$* * \mathrm{p}<0.01$ (2-tailed) (level of statistical significance).

$\mathrm{r}=$ correlation coefficient.

$\mathrm{p}=$ significance level.

\section{Comparative Analyses}

Comparison by gender

In Table 4, there was no statistically significant difference between male and female patients in terms of overall and sub-dimensions of patient satisfaction and patient commitment scale $(\mathrm{p}<0.05)$.

Table 4. Comparison by Gender $(N=280)$

\begin{tabular}{|c|c|c|c|c|c|c|}
\hline \multicolumn{2}{|c|}{ Scales and Sub-Dimensions } & $\mathbf{N}$ & $\begin{array}{l}\text { Mean } \\
\text { Rank }\end{array}$ & $\begin{array}{c}\text { Mann- } \\
\text { Whitney U }\end{array}$ & $\mathbf{Z}$ & $\mathbf{p}$ \\
\hline \multirow[b]{2}{*}{ Patient Satisfaction } & Male & 95 & 136.69 & \multirow{2}{*}{8426} & \multirow{2}{*}{-0.566} & \multirow{2}{*}{0.571} \\
\hline & Female & 185 & 142.46 & & & \\
\hline \multirow{2}{*}{ Medical Satisfaction } & Male & 95 & 129.88 & \multirow{2}{*}{7779} & \multirow{2}{*}{-1.621} & \multirow{2}{*}{0.105} \\
\hline & Female & 185 & 145.95 & & & \\
\hline \multirow{2}{*}{ Interest and Courtesy } & Male & 95 & 138.84 & \multirow{2}{*}{8630} & \multirow{2}{*}{-0.256} & \multirow{2}{*}{0.798} \\
\hline & Femal & 185 & 141.35 & & & \\
\hline \multirow{2}{*}{$\begin{array}{l}\text { Administrative } \\
\text { Satisfaction }\end{array}$} & Male & 95 & 138.00 & \multirow{2}{*}{8550} & \multirow{2}{*}{-0.376} & \multirow{2}{*}{0.707} \\
\hline & Female & 185 & 141.78 & & & \\
\hline \multirow{2}{*}{ Patient Commitment } & Male & 95 & 147.57 & \multirow{2}{*}{8116} & \multirow{2}{*}{-1.057} & \multirow{2}{*}{0.291} \\
\hline & Female & 185 & 136.87 & & & \\
\hline
\end{tabular}

Comparison by marital status

According to the Mann-Whitney $U$ test performed in terms of the marital status in Table 5, there was a statistically significant difference between both the scale scores and the sub-dimension scores $(p<0.01)$. Patient satisfaction and patient commitment vary according to marital status. When the general satisfaction scores were examined, the average of singles was higher than the average of those who were married. 
Table 5. Comparison by Marital Status ( $N=280)$

\begin{tabular}{|c|c|c|c|c|c|c|}
\hline \multicolumn{2}{|l|}{ Scales and Sub-Dimensions } & $\mathbf{N}$ & $\begin{array}{l}\text { Mean } \\
\text { Rank }\end{array}$ & \begin{tabular}{|c|} 
Mann- \\
Whitney U
\end{tabular} & $\mathbf{Z}$ & $\mathbf{p}$ \\
\hline \multirow{2}{*}{ Patient Satisfaction } & Married & 169 & 125.56 & \multirow{2}{*}{6855} & \multirow{2}{*}{-3.821} & \multirow{2}{*}{$0.000^{*}$} \\
\hline & Single & 111 & 163.24 & & & \\
\hline \multirow{2}{*}{ Medical Satisfaction } & Married & 169 & 128.19 & \multirow{2}{*}{7300} & \multirow{2}{*}{-3.237} & \multirow{2}{*}{$0.001^{*}$} \\
\hline & Single & 111 & 159.24 & & & \\
\hline \multirow{2}{*}{ Interest and Courtesy } & Married & 169 & 127.13 & \multirow{2}{*}{7120} & \multirow{2}{*}{-3.549} & \multirow{2}{*}{$0.000^{*}$} \\
\hline & Single & 111 & 160.86 & & & \\
\hline \multirow{2}{*}{ Administrative Satisfaction } & Married & 169 & 127.43 & \multirow{2}{*}{7170} & \multirow{2}{*}{-3.381} & \multirow{2}{*}{$0.001^{*}$} \\
\hline & Single & 111 & 160.41 & & & \\
\hline \multirow{2}{*}{ Patient Commitment } & Married & 169 & 125.08 & \multirow{2}{*}{6773} & \multirow{2}{*}{-3.967} & \multirow{2}{*}{$0.000^{*}$} \\
\hline & Single & 111 & 163.98 & & & \\
\hline
\end{tabular}

${ }^{*} \mathrm{p}<0.01$ (level of statistical significance).

Comparison by age

According to the Kruskal-Wallis $\mathrm{H}$ test conducted between age groups, a statistically significant difference was found in terms of both the general and subdimensions of patient satisfaction and the scale of patient commitment $(p<0.01)$. In the Bonferroni correction test conducted to reveal the source of the difference between the groups, 18-24 age group were numbered as 1; 25-31 age group as 2; 32-38 age group as 3; 39-45 age group as 4, and 46 age and above age group as 5 .

Accordingly, Bonferroni correction was found to be $0.05 / 5=0.01$ because of the number of groups in the variable (five). The results of the Mann-Whitney U test conducted to find the source of the difference are shown in Table 6 . In consonance with Table 6 , the source of the difference in both the general and subdimensions of patient satisfaction and the patient's commitment scale derived from the group of 18-24.

Patient satisfaction and its sub-dimensions, as well as patient commitment, the mean of 18-24 age group was higher than other age groups. Based on these results, patient satisfaction and patient commitment differ according to age.

\section{Comparison by education}

According to the Kruskal-Wallis $\mathrm{H}$ test conducted in terms of education status, a statistically significant difference was found concerning both the overall patient satisfaction and interest and courtesy sub-dimension $(\mathrm{p}<0.05)$. In the Bonferroni correction test conducted to reveal the source of the difference between the groups, the primary school was numbered as 1 , middle school as 2 , highschool as 3, bachelor's degree as 4 and master's degree as 5 . 
Table 6. Comparison by Age $(N=280)$

\begin{tabular}{|c|c|c|c|c|c|c|}
\hline \multicolumn{2}{|l|}{ Scales and Sub-Dimensions } & $\mathbf{N}$ & $\begin{array}{l}\text { Mean } \\
\text { Rank }\end{array}$ & $\begin{array}{l}\text { Chi- } \\
\text { square }\end{array}$ & $\mathbf{p}$ & Bonferroni \\
\hline \multirow{5}{*}{ Patient Satisfaction } & $18-24$ & 61 & 201.39 & \multirow{5}{*}{46.3} & \multirow{5}{*}{$0.000 *$} & \multirow{5}{*}{$\begin{array}{l}1-2(0.000)^{*} \\
1-3(0.000)^{*} \\
1-4(0.000)^{*} \\
1-5(0.000)^{*}\end{array}$} \\
\hline & $25-31$ & 50 & 123.40 & & & \\
\hline & $32-38$ & 58 & 116.22 & & & \\
\hline & $39-45$ & 55 & 135.98 & & & \\
\hline & 46 and over & 56 & 119.03 & & & \\
\hline \multirow{5}{*}{ Medical Satisfaction } & $18-24$ & 61 & 190.67 & \multirow{5}{*}{33.0} & \multirow{5}{*}{$0.000 *$} & \multirow{5}{*}{$\begin{array}{l}1-2(0.002)^{*} \\
1-3(0.000)^{*} \\
1-4(0.000)^{*} \\
1-5(0.000)^{*}\end{array}$} \\
\hline & $25-31$ & 50 & 125.37 & & & \\
\hline & $32-38$ & 58 & 121.34 & & & \\
\hline & $39-45$ & 55 & 135.96 & & & \\
\hline & 46 and over & 56 & 123.65 & & & \\
\hline \multirow{5}{*}{ Interest and Courtesy } & $18-24$ & 61 & 188.16 & \multirow{5}{*}{31.9} & \multirow{5}{*}{$0.000 *$} & \multirow{5}{*}{$\begin{array}{l}1-2(0.002)^{*} \\
1-3(0.000)^{*} \\
1-4(0.000)^{*} \\
1-5(0.000)^{*}\end{array}$} \\
\hline & $25-31$ & 50 & 135.89 & & & \\
\hline & $32-38$ & 58 & 129.46 & & & \\
\hline & $39-45$ & 55 & 131.21 & & & \\
\hline & 46 and over & 56 & 113.27 & & & \\
\hline \multirow{5}{*}{ Administrative Satisfaction } & $18-24$ & 61 & 195.13 & \multirow{5}{*}{37.8} & \multirow{5}{*}{$0.000 *$} & \multirow{5}{*}{$\begin{array}{l}1-2(0.000)^{*} \\
1-3(0.000)^{*} \\
1-4(0.000)^{*} \\
1-5(0.000)^{*}\end{array}$} \\
\hline & $25-31$ & 50 & 124.50 & & & \\
\hline & $32-38$ & 58 & 117.42 & & & \\
\hline & $39-45$ & 55 & 134.52 & & & \\
\hline & 46 and over & 56 & 125.05 & & & \\
\hline \multirow{5}{*}{ Patient Commitment } & $18-24$ & 61 & 207.41 & \multirow{5}{*}{58.1} & \multirow{5}{*}{$0.000 *$} & \multirow{5}{*}{$\begin{array}{l}1-2(0.002)^{*} \\
1-3(0.000)^{*} \\
1-4(0.000)^{*} \\
1-5(0.000)^{*}\end{array}$} \\
\hline & $25-31$ & 50 & 117.47 & & & \\
\hline & $32-38$ & 58 & 132.33 & & & \\
\hline & $39-45$ & 55 & 130.63 & & & \\
\hline & 46 and over & 56 & 106.34 & & & \\
\hline
\end{tabular}

$* \mathrm{p}<0.01$ (level of statistical significance).

Bonferroni correction was found to be $0.05 / 5=0.01$ because of the number of groups in the variable (five). The results of the Mann-Whitney U test conducted to find the source of the difference are shown in Table 7. Accordingly, the source of the difference in both the overall and sub-dimensions of patient satisfaction and interest and courtesy sub-dimension originated from primary school and the bachelor's degree. Based on these results, patient satisfaction and interest and courtesy vary according to education status. In the sub-dimension of administrative satisfaction, there was a significant difference. But the source of the difference was not found. In the dimension of medical satisfaction and patient commitment do not differ according to education status. The overall patient satisfaction scores of those with the bachelor's degrees were the highest, and of those with primary school students were the lowest. 
Table 7. Comparison by Education ( $N=280)$

\begin{tabular}{|c|c|c|c|c|c|c|}
\hline \multicolumn{2}{|c|}{ Scales and Sub-Dimensions } & \multirow{2}{*}{\begin{tabular}{l|}
$\mathbf{N}$ \\
73
\end{tabular}} & \multirow{2}{*}{$\begin{array}{c}\begin{array}{c}\text { Mean } \\
\text { Square }\end{array} \\
121.70 \\
\end{array}$} & \multirow{2}{*}{$\begin{array}{c}\text { Chi- } \\
\text { square }\end{array}$} & \multirow[t]{2}{*}{$\mathbf{p}$} & Bonferroni \\
\hline \multirow{5}{*}{ Patient Satisfaction } & Primary School & & & & & \multirow{5}{*}{$1-4(0.007)^{* *}$} \\
\hline & Middle School & 28 & 123.29 & \multirow{4}{*}{9.539} & \multirow{4}{*}{$0.049 *$} & \\
\hline & High-school & 50 & 150.53 & & & \\
\hline & Bachelor's & 118 & 153.51 & & & \\
\hline & Master's Degree & 11 & 123.91 & & & \\
\hline \multirow{5}{*}{ Medical Satisfaction } & Primary School & 73 & 134.67 & \multirow{5}{*}{2.642} & \multirow{5}{*}{0.619} & \\
\hline & Middle School & 28 & 122.96 & & & \\
\hline & High-school & 50 & 142.99 & & & \\
\hline & Bachelor's & 118 & 146.76 & & & \\
\hline & Master's Degree & 11 & 145.32 & & & \\
\hline \multirow{5}{*}{ Interest and Courtesy } & Primary School & 73 & 113.45 & \multirow{5}{*}{12.975} & \multirow{5}{*}{$0.011^{*}$} & \multirow{5}{*}{$1-4(0.001)^{* * *}$} \\
\hline & Middle School & 28 & 147.23 & & & \\
\hline & High-school & 50 & 144.61 & & & \\
\hline & Bachelor's & 118 & 154.36 & & & \\
\hline & Master's Degree & 11 & 135.45 & & & \\
\hline \multirow{5}{*}{$\begin{array}{l}\text { Administrative } \\
\text { Satisfaction }\end{array}$} & Primary School & 73 & 125.38 & \multirow{5}{*}{12.162} & \multirow{5}{*}{$0.016^{*}$} & \\
\hline & Middle School & 28 & 106.89 & & & \\
\hline & High-school & 50 & 154.80 & & & \\
\hline & Bachelor's & 118 & 152.76 & & & \\
\hline & Master's Degree & 11 & 129.86 & & & \\
\hline \multirow{5}{*}{ Patient Commitment } & Primary School & 73 & 128.50 & \multirow{5}{*}{9.006} & \multirow{5}{*}{0.061} & \\
\hline & Middle School & 28 & 121.54 & & & \\
\hline & High-school & 50 & 142.00 & & & \\
\hline & Bachelor's & 118 & 154.95 & & & \\
\hline & Master's Degree & 11 & 106.55 & & & \\
\hline
\end{tabular}

${ }^{*} \mathrm{p}<0.05$ (level of statistical significance).

$* * \mathrm{p}<0.01$ (level of statistical significance).

Comparison by recently visited hospital

According to the Kruskal-Wallis $\mathrm{H}$ test conducted in terms of the hospital visited recently, it was found a statistically significant difference in terms of both the overall patient satisfaction and sub-dimensions and patient commitment $(\mathrm{p}<0.05)$. In the Bonferroni correction test conducted to reveal the source of the difference between the groups, public hospital was numbered as 1, private hospital as 2, and university hospital as 3 .

Accordingly, Bonferroni correction was found to be $0.05 / 3=0.017$ because of the number of groups in the variable (three). The results of the Mann-Whitney $U$ test conducted to find the source of the difference is shown in Table 8. The source of the difference in both the general and sub-dimensions of patient satisfaction and patient commitment derived from the public hospital-the private hospital and the public hospital-the university hospital. But the source of the difference in interest and courtesy dimension originated from the public hospital-the private hospital. Looking at these comparisons, in terms of patient satisfaction and patient commitment, the approaches of the patients visiting the public hospital and the university hospital were close to each other. Only in the interest and courtesy dimension, there was a significance in terms of the patients visiting the public and private hospital. 
When viewed on average values, the average satisfaction of those who applied to the public and university hospitals was higher than those admitted to the private hospital.

Based on these results, patient satisfaction and sub-dimensions differed according to the hospital that was last visited.

Table 8. Comparison by Recently Visited Hospital $(N=280)$

\begin{tabular}{|c|c|c|c|c|c|c|}
\hline \multicolumn{2}{|c|}{ Scales and Sub-Dimensions } & $\mathbf{N}$ & $\begin{array}{l}\text { Mean } \\
\text { Rank }\end{array}$ & \begin{tabular}{|c} 
Chi- \\
square
\end{tabular} & $\mathbf{p}$ & Bonferroni \\
\hline \multirow{3}{*}{ Patient Satisfaction } & Public Hospital & 101 & 165.52 & \multirow{3}{*}{54.876} & \multirow{3}{*}{$0.000 *$} & \multirow{3}{*}{$\begin{array}{l}1-2(0.000)^{*} \\
2-3(0.000)^{*}\end{array}$} \\
\hline & Private Hospital & 73 & 80.58 & & & \\
\hline & \begin{tabular}{|l|} 
University Hospital \\
\end{tabular} & 106 & 157.92 & & & \\
\hline \multirow{3}{*}{ Medical Satisfaction } & Public Hospital & 101 & 152.56 & \multirow{3}{*}{27.088} & \multirow{3}{*}{$0.000^{*}$} & \multirow{3}{*}{$\begin{array}{l}1-2(0.000) * \\
2-3(0.000)^{*}\end{array}$} \\
\hline & \begin{tabular}{|l} 
Private Hospital \\
\end{tabular} & 73 & 99.52 & & & \\
\hline & University Hospital & 106 & 157.23 & & & \\
\hline \multirow{3}{*}{ Interest and Courtesy } & Public Hospital & 101 & 157.81 & \multirow{3}{*}{13.372} & \multirow{3}{*}{$0.001 *$} & \multirow{3}{*}{$1-2(0.000)^{*}$} \\
\hline & Private Hospital & 73 & 114.24 & & & \\
\hline & University Hospital & 106 & 142.09 & & & \\
\hline \multirow{3}{*}{$\begin{array}{l}\text { Administrative } \\
\text { Satisfaction }\end{array}$} & Public Hospital & 101 & 161.52 & \multirow{3}{*}{50.962} & \multirow{3}{*}{$0.000 *$} & \multirow{3}{*}{$\begin{array}{l}1-2(0.000)^{*} \\
2-3(0.000)^{*}\end{array}$} \\
\hline & Private Hospital & 73 & 83.32 & & & \\
\hline & University Hospital & 106 & 159,85 & & & \\
\hline \multirow{3}{*}{ Patient Commitment } & Public Hospital & 101 & 161.27 & \multirow{3}{*}{40.917} & \multirow{3}{*}{$0.000^{*}$} & \multirow{3}{*}{$\begin{array}{l}1-2(0.000)^{*} \\
2-3(0.000)^{*}\end{array}$} \\
\hline & Private Hospital & 73 & 88.96 & & & \\
\hline & University Hospital & 106 & 156.21 & & & \\
\hline
\end{tabular}

*p<0.01 (level of statistical significance).

Comparison by monthly average income status

As a result of the Kruskal-Wallis $\mathrm{H}$ test conducted according to the monthly average income status in Table 9, there was no statistically significant difference between the overall patient satisfaction and sub-dimensions and patient commitment $(\mathrm{p}>0.05)$.

\section{Regression Analysis}

Using the Enter method in the regression analyses, it was observed the success of foreseeing the model by adding independent variables in the model and the rate of change that each independent variable occurred on the dependent variable (Karagöz 2016). Firstly, it was examined the effect of overall patient satisfaction on the scale of patient commitment by conducting simple linear regression analysis, and then the effect on the patient commitment of the subdimensions of patient satisfaction by multiple regression analysis. 
Table 9. Comparison by Monthly Average Income Status ( $N=280)$

\begin{tabular}{|c|c|c|c|c|c|}
\hline \multicolumn{2}{|l|}{ Scales and Sub-Dimensions } & \multirow{2}{*}{$\frac{\mathbf{N}}{21}$} & \multirow{2}{*}{\begin{tabular}{c|} 
Rank Mean \\
158.31
\end{tabular}} & \multirow[t]{2}{*}{ Chi-square } & \multirow[t]{2}{*}{$\mathbf{p}$} \\
\hline \multirow{5}{*}{ General Satisfaction } & $0-1600 \mathrm{TL}$ & & & & \\
\hline & $1601-2500 \mathrm{TL}$ & 82 & 138.40 & \multirow{4}{*}{2.484} & \multirow{4}{*}{0.648} \\
\hline & $2501-3500 \mathrm{TL}$ & 89 & 144.80 & & \\
\hline & $3501-4500 \mathrm{TL}$ & 44 & 140.28 & & \\
\hline & 4501 TL and above & 44 & 127.43 & & \\
\hline \multirow{5}{*}{ Medical Satisfaction } & $0-1600 \mathrm{TL}$ & 21 & 149.83 & \multirow{5}{*}{1.999} & \multirow{5}{*}{0.736} \\
\hline & $1601-2500 \mathrm{TL}$ & 82 & 142.66 & & \\
\hline & $2501-3500 \mathrm{TL}$ & 89 & 141.66 & & \\
\hline & $3501-4500 \mathrm{TL}$ & 44 & 144.26 & & \\
\hline & 4501 TL and above & 44 & 125.91 & & \\
\hline \multirow{5}{*}{ Interest and Courtesy } & $0-1600 \mathrm{TL}$ & 21 & 135.31 & \multirow{5}{*}{5.131} & \multirow{5}{*}{0.274} \\
\hline & $1601-2500 \mathrm{TL}$ & 82 & 125.45 & & \\
\hline & $2501-3500 \mathrm{TL}$ & 89 & 150.46 & & \\
\hline & $3501-4500 \mathrm{TL}$ & 44 & 142.86 & & \\
\hline & 4501 TL and above & 44 & 148.51 & & \\
\hline \multirow{5}{*}{ Administrative Satisfaction } & $0-1600 \mathrm{TL}$ & 21 & 176.14 & \multirow{5}{*}{4.980} & \multirow{5}{*}{0.289} \\
\hline & $1601-2500 \mathrm{TL}$ & 82 & 140.04 & & \\
\hline & $2501-3500 \mathrm{TL}$ & 89 & 139.58 & & \\
\hline & $3501-4500 \mathrm{TL}$ & 44 & 135.66 & & \\
\hline & 4501 TL and above & 44 & 131.05 & & \\
\hline \multirow{5}{*}{ Patient Commitment } & $0-1600 \mathrm{TL}$ & 21 & 153.86 & \multirow{5}{*}{3.105} & \multirow{5}{*}{0.540} \\
\hline & $1601-2500 \mathrm{TL}$ & 82 & 135.23 & & \\
\hline & $2501-3500 \mathrm{TL}$ & 89 & 148.87 & & \\
\hline & $3501-4500 \mathrm{TL}$ & 44 & 127.23 & & \\
\hline & 4501 TL and above & 44 & 140.31 & & \\
\hline
\end{tabular}

Effect of patient satisfaction on patient commitment

Table 10 shows the results of the regression analysis conducted to find whether patient satisfaction affects patient commitment. It was statistically significant the regression model established according to the result of the analysis $(\mathrm{F}(1.278)=327.849 ; \mathrm{p}<0.000)$. According to the results of the analysis, patient satisfaction affects patient commitment $(B=0.918 ; \mathrm{p}<0.01) .54 .1 \%$ of patient commitment is explained by patient satisfaction, according to the regression model. Patient satisfaction makes changes by $91.8 \%$ in patient commitment. To explain the change of $8.2 \%$ is needed for other variables.

Table 10. Effect of Patient Satisfaction on Patient Commitment

\begin{tabular}{|c|c|c|c|c|c|c|c|c|}
\hline $\begin{array}{l}\text { Dependent } \\
\text { Variable }\end{array}$ & $\begin{array}{l}\text { Independent } \\
\text { Variable }\end{array}$ & $\mathbf{R}^{2}$ & $\begin{array}{c}\text { Adjusted } \\
\mathbf{R}^{2}\end{array}$ & $\mathbf{F}$ & $\mathbf{p}$ & B & $\mathbf{t}$ & $\mathbf{p}$ \\
\hline \multirow{2}{*}{$\begin{array}{l}\text { Patient } \\
\text { Commitment }\end{array}$} & Constant & \multirow[b]{2}{*}{0.541} & \multirow[b]{2}{*}{0.544} & \multirow[b]{2}{*}{327.849} & \multirow[b]{2}{*}{$0.000 *$} & -2.527 & -1.500 & 0.135 \\
\hline & $\begin{array}{l}\text { Patient } \\
\text { Satisfaction }\end{array}$ & & & & & 0.918 & 18.107 & $0.000 *$ \\
\hline
\end{tabular}

Multiple regression analysis

Table 11 presents the results of multiple regression analysis to determine whether the sub-dimensions of patient satisfaction affect patient commitment. The regression modelled was statistically found significant $(F(3.276)=111.810 ; p<0.000)$, 
according to the result of the analysis. $\mathrm{R}^{2}=0.549$ shows the fit of the model is moderate.

Table 11. Multiple Regression Analysis

\begin{tabular}{|c|c|c|c|c|c|c|c|c|c|c|}
\hline $\begin{array}{l}\text { Pependent } \\
\text { ariable }\end{array}$ & $\begin{array}{l}\text { ndependent } \\
\text { Tariable }\end{array}$ & $\mathbf{R}^{2}$ & $\begin{array}{c}\text { Adjusted } \\
\mathbf{R}^{2}\end{array}$ & $\mathbf{F}$ & p & B & Tolerance & VIF & $\mathbf{t}$ & $\mathbf{p}$ \\
\hline \multirow{4}{*}{$\begin{array}{l}\text { Patient } \\
\text { Commitment }\end{array}$} & Constant & \multirow{4}{*}{0.549} & \multirow{4}{*}{0.544} & \multirow{4}{*}{111.810} & 0.058 & & & & & \multirow{4}{*}{0.000} \\
\hline & $\begin{array}{l}\text { Medical } \\
\text { Satisfaction }\end{array}$ & & & & 0.000 & 0.292 & 0.765 & 1.307 & 6.312 & \\
\hline & $\begin{array}{l}\text { Interest and } \\
\text { Courtesy }\end{array}$ & & & & 0.000 & 0.322 & 0.801 & 1.248 & 7.125 & \\
\hline & $\begin{array}{l}\text { Administrative } \\
\text { Satisfaction }\end{array}$ & & & & 0.000 & 0.339 & 0.708 & 1.413 & 7.059 & \\
\hline
\end{tabular}

This model developed according to the adjusted $\mathrm{R}^{2}$ model would explain $54.4 \%$ of the total variance if produced from the universe instead of the sample. Because of the Variance of Inflation Factor (VIF) is less than 10, and the tolerance statistics are over 0.2 in sub-dimensions of the scale, it shows there is no problem in this model. Therefore, there is no need to correct the independent variables (Karagöz 2016). The sub-dimensions of patient satisfaction affect patient commitment $(\mathrm{B}=0.292 ; 0.322 ; 0.339 ; \mathrm{p}<0.01)$, according to the results of the analysis. $54.1 \%$ of patient commitment is explained by patient satisfaction, according to the regression model. Of the sub-dimensions of patient satisfaction, medical satisfaction makes changes of $29.2 \%$ in the patient commitment, interestcourtesy in $32.2 \%$, and administrative satisfaction in $33.9 \%$.

\section{Discussion and Conclusion}

It was examined the effect of patient satisfaction on patient commitment according to the hospital where patients visited in Konya province.

According to the results obtained from the study, $80 \%$ of the participants are under the age of 45 and approximately $2 / 3$ of them are female and $40 \%$ of them are single. When examined the education level of the participants, the highest rate is in the bachelors' group (42.1\%) and the lowest (3.9\%) in the masters' degree. The ratio of primary and middle school graduates is more than $1 / 3$. When examined the hospital last visited, the rate of those visiting the university hospital is higher than the others, but it is very close to the public hospital. When examined the average monthly income, the ratio of those who are up to $1.600 \mathrm{TL}$ is the lowest.

In the study conducted by Jung and Sung (2018), a significant relationship was found between patient satisfaction and patient commitment in nursing services in the hospital. According to the results of the study conducted by Pao-Chun et al. (2018), there was a significant relationship between patient commitment and patient satisfaction $(r=0.768 ; p<0.01)$. Similar results confirming our study were found.

Patient satisfaction and patient commitment differed according to marital status, age, and recently visited the hospital $(\mathrm{p}<0.01)$. According to the education 
level, there was a significant difference in overall satisfaction and sub-dimensions of interest and courtesy, and administrative satisfaction ( $p<0.05)$. It was not found a significant difference according to gender and monthly average income $(p>0.05)$. As an example, while some studies have concluded that women are more satisfied, in some studies men are more satisfied, while others have no relationship between gender and satisfaction (Y1lmaz 2001).

Looking at the overall satisfaction scores, the average of those who are single is considerably higher than the average of those who are married. The source of difference in both the overall patient satisfaction and the sub-dimensions and patient commitment is the group of 18-24. With patient satisfaction and the subdimensions, the mean of the 18-24 age group in patient commitment is higher than other age groups. The source of the difference both in the overall patient satisfaction and the sub-dimension of interest and courtesy are those who are graduates of primary school and bachelors.

The source of the difference both in overall patient satisfaction and subdimensions and patient commitment is public hospital-private hospital and private hospital-university hospital. The source of difference in interest and courtesy subdimension is the public hospital-private hospital. Looking at these comparisons, approaches of those visited a public hospital and university hospital in terms of patient satisfaction and patient commitment are close to each other; nothing but, there is significance in terms of patients visiting a public hospital and private hospital in the dimension of interest and courtesy. Examining the average values, the average of satisfaction from the health service of those who apply to public and university hospitals is higher than those who admit to a private hospital. Contrary to our study, according to a study conducted on those receiving outpatient service from a public and a private hospital in Kahramanmaras province, those who admitted to the private hospital had higher interest and kindness than those applied to the public hospital and it was concluded the service provided by physicians was more satisfactory (Taşlıyan and Gök 2014).

According to the result of our study was reached that patient commitment was influenced by the administrative satisfaction, interest and courtesy, and the satisfaction of medical services, respectively. According to the study conducted by Erdem et al. (2008) were obtained the result that interest and kindness dimension highly affected patient commitment, then the satisfaction of the administrative services and the satisfaction with medical services, respectively. In the study conducted by Lestariningsih et al. (2018) it was found that patient satisfaction had a positive effect on patient commitment $(\mathrm{p}=0.003$; path coefficient $=0.296)$. In the study conducted by Pao-Chun et al. (2018) similarly, it was found that patient satisfaction had a positive impact on patient commitment $(\beta=0.239, \mathrm{p}=0.00)$. In similar studies conducted by Pramita (2019) ( $\mathrm{p}=0.011 ; \mathrm{r}=0.275)$ and Ramli (2017) $(\mathrm{p}<0.05 ; \mathrm{t}=2.5492)$, it was found that patient satisfaction had a positive and significant effect on patient commitment. In the study conducted by Juhana et al. (2015), they concluded that patient satisfaction had a $76.1 \%$ effect on patient commitment. According to the results of the study conducted by Dachyar et al. (2018) patients' satisfaction affects patient commitment. Hossain et al. (2019) found that the satisfaction of patients in Bangladesh had a positive influence on 
their' commitment to the health-care providers in their study. Permana et al. (2019) and Mahendrayana et al. (2018) found that patient satisfaction had a positive and significant effect on patient commitment.

In a similar study conducted by the Tüfekçi and Asığbulmuş (2016), the first three factors that are most effective in hospital preference are in order of trust, expert physician preference, and satisfaction. The three factors that are effective not to re-prefer the hospital are in order of the absence of physician apathy, insufficient examination, and tolerance.

The results of the study cannot be generalized to the universe, since it is limited to patients receiving treatment services from public, private, and university hospitals in Karatay District center in Konya Province in January 2019. It is necessary to work with large sampling numbers that can represent the universe to generalize. For researchers, similar studies are recommended in patients receiving both outpatient healthcare services and primary care services in hospitals.

\section{References}

Allen NJ, Meyer JP (1990) The measurement and antecedents of affective, continuance and normative commitment to the organization. Journal of Occupational Psychology 63(1): 1-18.

Allen NJ, Meyer JP (1996) Affective, continuance, and normative commitment to the organization: an examination of construct validity. Journal of Vocational Behavior 49(3): 252-276.

Aslan Ş, Sezgin M, Haşıloğlu SB (2008) Özel sağlık kuruluşlarında müşteri memnuniyeti ve memnuniyeti oluşturan unsurların araştırılması (Investigation of customer satisfaction and satisfaction factors in private health institutions). Muğla Üniversitesi Sosyal Bilimler Enstitüsü Dergisi (ILKE) 20: 23-40.

Boshoff C, Gray B (2004) The relationship between service quality, customer satisfaction and buying intentions in the private hospital industry. South African Journal of Business Management 35(4): 27-37.

Büber R, Başer H (2012) Customer satisfaction in health enterprises: an application in a foundation university hospital. Sosyal ve Beşeri Bilimler Dergisi 4(1): 265-274.

Ceylan A, Çöl G, Gül H (2005) A study on the effects of the social-structural characteristics determining the meaningfulness of work on empowerment and the results of these effects. Doğuş University Journal 6(1): 35-51.

Dachyar MF, Farizal FF, Minar IP (2018) Patients' loyalty improvement in public hospital. $4^{\text {th }}$ Engineering Science and Technology International Conference 248: 1-5.

Derin N, Demirel ET (2011) Examination of the Relationship of hospital reputation created by patient opinions with patient attitudes and behaviors case study: Turgut Özal Medical Center. Firat University Journal of Social Science 21(2): 208-235.

Erdem R, Rahman S, Avci L, Demirel B, Köseoğlu S, Firat G et al. (2008) The effect of patient satisfaction on patient commitment. Erciyes University Journal of Faculty of Economics and Administrative Sciences 31: 95-110.

Esatoğlu AE (1997) Evaluation of patient satisfaction in hospital as regards to hospital administration and a suggestion of a practical model. Hacettepe University Institute of Health Sciences, Unpublished Doctoral Dissertation. 
Gülmez M (2005) Satisfaction measurement in health service and an application to the clinic for out-patients at cumhuriyet university hospital. Cumhuriyet University Journal of Economics and Administrative Sciences 6(2): 147-169.

Hebert JS (2015) Advancing interprofessional collaboration in nursing education. Athens Journal of Health 2(4): 239-260.

Hossain M, Yahya S, Khan M (2019) The effect of corporate social responsibility (csr) health-care services on patients' satisfaction and loyalty - a case of Bangladesh. Social Responsibility Journal (in press).

Juhana D, Manik E, Febrinella C, Sidharta I (2015) empirical study on patient satisfaction and patient loyalty on public hospital in Bandung, Indonesia. International Journal of Applied Business and Economic Research 13(6): 4305-4326.

Jung YA, Sung KM (2018) A comparison of patients' nursing service satisfaction, hospital commitment and revisit intention between general care unit and comprehensive nursing care unit. Journal of Korean Academy of Nursing Administration 24(1): 3039.

Kandampully J, Hu HH (2007) Do hoteliers need to manage image to retain loyal customers? International Journal of Contemporary Hospitality Management 19(6): 435-443.

Karagöz Y (2016) SPSS 23 ve AMOS 23 uygulamal istatistiksel analizler (SPSS 23 and AMOS 23 applied statistical analysis). Ankara: Nobel Yayinevi.

Kavuncubaşı Ş, Yıldırım, S (2012) Hastane ve sağllk kurumları yönetimi (Hospital and health institutions management). Siyasal Kitabevi.

Kılıç T, Topuz, R (2016) Effect of communication with patients on patient satisfaction: a comparison of private, state and university hospitals. Sağlikta Performans ve Kalite Dergisi 9(1): 78-95.

Kısa A (2007) Sağllk kurumları yönetimi (Health institutions management). Eskisehir: Anadolu University Open Education Publications.

Korkmaz Ş (2003) Human resources management applications at health institutions and a research related to the subject at private hospitals which have 50 and more than 50 beds in Istanbul. Istanbul University Institute of Social Sciences Unpublished Master Dissertation.

Lestariningsih T, Hadiyati E, Astuti R (2018) Study of service quality and patient satisfaction to trust and loyalty in public hospital, Indonesia. International Journal of Business Marketing and Management 3(2): 1-12.

Macmillan K, Money K, Money A, Downing S (2005) Relationship marketing in the notfor-profit sector: an extension and application of the commitment-trust theory. Journal of Business Research 58(6): 806-818.

Mahendrayana IMA, Yasa PNS, Indiani LP (2018) The effect of service quality on patient loyalty mediated by patient satisfaction in Bali Siloam hospital. Jurnal Ekonomi \& Bisnis 5(1): 1-7.

Oliver RL (1997) Satisfaction: A Behavioural Perspective on the Consumer. McGraw Hill, New York: Routledge.

Öz M (2004) Hasta memnuniyeti ve sskb Ankara eğitim hastanesinde bir uygulama (Patient satisfaction and an application in ssk Ankara training hospital). Gazi University Institute of Social Sciences. Unpublished Master Dissertation.

Özata M, Özer K (2017) Investigation of the attitudes of health care staff about patient privacy. Hacettepe Journal of Health Administration 20(1): 81-92.

Özer A, Çakıl E (2007) Sağlik hizmetlerinde hasta memnuniyetini etkileyen faktörler (Factors affecting patient satisfaction in health services). Tip Araştırmaları Dergisi 5(3): 140-143. 
Öztürk YE (2014) Perceived service quality in health and the reasons for choosing a hospital. Gümüshane University Journal of Health Sciences 3(4): 1079-1094.

Pao-Chun H, Yii-Ching L, Hsin-Hung W, Chih-Hsuan H, Li L (2018) Establishing patient loyalty by investigating its relationship with relationship quality, alternative attractiveness, and patient gratitude in hospitals. International Journal of $e$ Education, e-Business, e-Management and e-Learning 8(1): 58-65.

Permana AW, Suardika N, Sujana W, Yuesti A (2019) Analysis of service quality and value effect on patient satisfaction and its effect on loyalty of hospital patients in hospital and children of pucuk permata hati. International Journal of Contemporary Research and Review 10(2): 21255-21266.

Pramita P (2019) Effect of experience in building satisfaction, trust, and loyalty. Jurnal Aplikasi Manajemen 17(1): 76-86.

Ramez WS (2012) Patients' perception of health care quality, satisfaction and behavioral intention: an empirical study in Bahrain. International Journal of Business and Social Science 3(18): 131-141.

Ramli AH (2017) Patient satisfaction, hospital image and patient loyalty in west Sulawesi province. Business and Entrepreneurial Review 17(1): 1-14.

Resmi Gazete, 12.01.1961 Tarih ve 10705 Sayll, 224 Sayll Sağlık Hizmetlerinin Sosyalleştirilmesi.

Resmi Gazete, 01.08.1998 Tarih ve 23420 Sayıl, Hasta Hakları Yönetmeliği.

Taşliyan M, Gök S (2014) Patient satisfaction in public and private hospitals: a field study in Kahramanmaras. Kahramanmaraş Sütçü İmam University Faculty of Economics and Administrative Sciences Journal 2(1): 69-94.

Teke A, Uçar M, Demir C, Çelen Ö, Karaalp T (2007) Evaluation of knowledge and attitudes of the nurses working in a training hospital about patients' rights. TAF Preventive Medicine Bulletin 6(4): 259-266.

Teutsch C (2003) Patient-doctor communication. Medical Clinics of North America 87(5): $1115-1146$.

Tüfekçi N, Asiğbulmuş H (2016) The factors that effective in the choice of hospital and patient satisfaction: the sample of Isparta. Journal of Current Researches on Health Sector 6(2): 71-92.

Uysal B, Yorulmaz M (2018) Health quality standards and cognitive confidentiality. Selcuk University the Journal of Social and Technical Researches 16: 24-33.

Yıldırım-Kaptanoğlu A, İşçi E (2013) Sağllk alaninda hipotezden teze: veri toplama ve çözümleme serüveni (From hypothesis to health in the field of health: data collection and analysis adventure). Beşir Kitabevi, İstanbul: Beşir Kitabevi.

Yllmaz M (2001) Patient satisfaction: a criterion of health care quality. Journal of Cumhuriyet University School of Nursing 5(2): 69-74. 


\title{
Comparing Traditional Cognitive Behavior Therapy with Mindfulness-Based Interventions as a Treatment Option for Anxiety Disorders in Pediatric Patients ${ }^{1}$
}

\author{
By Timothy Zeiger*, Ailyn Diaz ${ }^{ \pm}$, Meenal Pathak ${ }^{*}$, Daisy Shirk ${ }^{+}$, \\ Jasmin Lagman ", Jolene M. Hillwig-Garcia ' Himadri Patel \\ \& Lidija Petrovic-Dovat ${ }^{\star}$
}

Nearly one in three adolescents meets the criteria for an anxiety disorder (31.9\%) according to the National Institute of Mental Health, and it is commonly underdiagnosed and untreated. The use of behavioral therapies such as Cognitive Behavioral Group Therapy $(C B G T)$ and mindfulness-based group interventions (MBIs) is on the raise with more evidence showing the effectiveness of these therapies. The first aim of this review is to assess the effectiveness of an MBI in adolescents with anxiety disorders and chronic illness. The second aim is to look at the differences in outcomes of MBI and standard $C B G T$ in adolescent patients with anxiety disorders. For the first aim, we performed a literature search for studies comparing MBI with CBGT in the treatment of children and adolescents. For the second aim, we assess the effectiveness of MBIs in adolescent patients at our Academic Center by performing a retrospective chart review of the ratings on the SCARED (Screen for Child Anxiety Related Disorders) scale before and after a MBI in 8-week group therapy immediately following CBT. The data was compared to our previous published results from patients who underwent CBT treatment alone. Two out of six participants completed the pre-and post-group session SCARED rating scale. This was due to the high dropout rate, which is not uncommon for group therapy. There was an overall decrease in total anxiety scores in the MBI group in our limited sample size compared to CBT group results previously reported. A major limitation of our study is a high dropout rate not uncommon in this patient population. Additional studies comparing these two treatments are needed, especially considering limited available literature comparing these two therapy approaches.

Keywords: Mindfulness, Chronic illness, Children and adolescents, Anxiety, Cognitive behavioral therapy

\section{Introduction}

More than one-third of adolescents in the United States have at least one lifetime mental disorder and one-lifetime physical illness with anxiety being the most prevalent mental health disorder (Tegethoff 2015). A recent international

*Psychologist, PLLC, Hershey, PA, USA.

${ }^{ \pm}$Assistant Professor, College of Medicine, Pennsylvania State University, USA.

*Assistant Professor, College of Medicine, Pennsylvania State University, USA.

${ }^{+}$Assistant Professor, College of Medicine, Pennsylvania State University, USA.

-Assistant Professor, College of Medicine, Pennsylvania State University, USA.

Assistant Professor, College of Medicine, Pennsylvania State University, USA.

- Medical Student, Pennsylvania State University, USA.

^Associate Professor, College of Medicine, Pennsylvania State University, USA.

${ }^{1}$ Timothy Zeiger \& Ailyn Diaz contributed equally to this work. 
systematic review found that prevalence rates of anxiety disorder in chronic medical health conditions affect $20 \%$ to $50 \%$ of children and adolescents (Cobham et al. 2019). Chronic illness is considered a health issue that is not yet curable and lasts around three months, affects a child's activities and requires frequent hospitalizations, which can lead to home care and vast health care needs (Mokkink et al. 2008). Advances in medical outcomes including early detection and diagnosis have led many children and adolescents to live and cope with chronic illness. Children and adolescents with chronic illness cope with school absenteeism, medical procedures, multiple hospitalizations, drug interventions and restriction of usual activities. In a seminal article on cognitive coping strategies, within a year of treatment, some of these children, developed skills in problem-solving and emotional regulation and were able to manage their illness leading to higher confidence and improved self-esteem (LeBlanc et al. 2003).

The leading theoretical scheme of stress and cognitive appraisal proposes that not all children are able to cope with stressors or develop cognitive appraisal, the main cognitive process that mediates the stress reaction (Lazarus and Folkman 1984). According to a meta-analysis of 332 studies, children with chronic illness compared to healthy peers have elevated levels of anxiety with the highest being in those with chronic fatigue syndrome, epilepsy, migraine/tension headaches, and sensory impairment (Pinquart and Shen 2011). An increased rate of behavioral problems in children and adolescents with chronic illnesses suggests that dysfunctional cognitive strategies such as catastrophizing are used to cope. This finding corresponds with a major cross-sectional study on chronic illness in which anxious anticipation, avoidance, worry, rumination and fear of consequences were used by children and adolescents as main coping strategies (Olson et al. 1993).

\section{Literature Review}

Cognitive behavioral therapy challenges dysfunctional coping strategies. In a review of psycho-educational interventions, cognitive behavioral strategies lead to higher effectiveness in adaptation of chronic illness and improved outcomes in children and adolescents with chronic illnesses, which were maintained at a year follow up (Barlow and Ellard 2004). In the Op Koers trial (in English: On Track), children and adolescents with chronic illness were taught active use of cognitive behavioral strategies aimed at improving self-management, social competence and positive thinking (Scholten et al. 2011).

Coping strategies tend to be equal in both healthy peers and those with chronic illness since common experiences such as bullying and feeling isolated are shared among youth (Olson et al. 1993). Chronic illness is conceptualized as a whole and not under specific diagnostic categories (Barlow and Ellard 2004). Similar to a multicenter randomized controlled trial, which examined cognitive behavioral based group interventions for children and their parents (Scholten et al. 2011), our study grouped chronic illnesses under one general category.

Although cognitive behavioral therapy is the most evidence-based psychotherapy known to reduce symptoms of anxiety (van den Brink et al. 2016), 
there are few studies examining chronic illness and anxiety in children. In a pilot study of nine children displaying a disease specific diagnosis of inflammatory bowel disease and anxiety, $88 \%$ were treatment responders while half showed no signs of anxiety after treatment intervention (Reigada et al. 2013). Another study with children with anxiety and epilepsy utilized computerized cognitive behavioral therapy as an intervention. While the study showed a reduction in anxiety at the end of the intervention, it also showed an overall reduction in total problematic child behavior on the Child Behavioral Checklist (Blocher et al. 2013). In a systematic review of psychological interventions, only one study utilized group cognitive behavioral therapy matching controls of children with anxiety and asthma and children with anxiety alone, showing a significant reduction in the clinical global impression scale (Bennett et al. 2015).

Unlike cognitive behavioral therapy which is mostly individual based interventions, mindfulness is generally taught in groups (Thompson and GauntlettGilbert 2008). Mindfulness can be defined as "paying attention in a particular way: on purpose in the present moment, and nonjudgmentally" (Kabat-Zinn 1994). It differs from cognitive behavioral therapy in that it recognizes problematic thoughts without changing them. Mindfulness based therapy is a mode of acceptance and awareness of thinking in contrast to cognitive behavioral approaches that challenge the content of thoughts (Thompson and Gauntlett-Gilbert 2008). Mindfulness based strategies lend to engagement and group cohesion in children and adolescents (Wagner et al. 2006). It leads to sharing experiences in which members can learn and support one another (Semple et al. 2006).

Mindfulness based interventions include meditation-based strategies such as nonjudgmental diaphragmatic breathing with focused attention, self-regulation of emotions and general self-awareness. These strategies are associated with a reduction in stress and negative emotions, improvement in patient attitude, healthrelated behavior and coping skills in individuals with diabetes (Priya and Kalra 2018). Only one pilot study in mindfulness meditation showed efficacy with improvement mood and quality of life as reported by parents in a group of adolescents. It also leads to a reduction of inflammatory factors: IL-1 B, IL-6 and TNF-alpha levels (Sansone et al. 2018).

An electronic database search on Medline OVID and PubMed showed no published studies as to the addition of mindfulness meditation-based strategies to cognitive behavioral therapy in children and adolescents with anxiety and chronic illness making our study unique. The estimated lifetime prevalence of anxiety disorders in children is $31.9 \%$ (Merikangas et al. 2010). If left untreated, it can have a negative impact on a child's life (van Beljouw et al. 2010). Children and adolescents with chronic illness face many of physical and emotional challenges after diagnosis and during treatment. Children with chronic health conditions are at an increased risk of depression and other mental health problems later in life.

\section{Objectives}

The first objective of this study was to assess the effectiveness of a Mindfulness Cognitive Behavior Therapy Groups for children and adolescents 
with an anxiety disorder and chronic illnesses and/or Tourette syndrome. Due to the small sample size of the group who responded to recruitment there was no patient in the group with Tourette syndrome. The group consisted solely of children and adolescents with anxiety and/or chronic illnesses.

This research study attempted to compare outcomes from a previous published study by Scales et al. (2018) where Cognitive Behavior Therapy groups were offered to determine the effectiveness of CBGT sessions for children and adolescents with Social Anxiety Disorder (SAD) and Generalized Anxiety Disorder (GAD) to the Mindfulness group therapy for children with anxiety and chronic illness

The second objective aim was to perform literature searches and identify the publications comparing Mindfulness with Cognitive Behavioral Therapy for treatment of children and adolescents with the focus on children with anxiety and chronic illness.

\section{Methodology}

This study was approved by the Institutional Review Boards of Penn State Milton S. Hershey Medical Center and Penn State College of Medicine.

Eligible subjects were identified through Hershey Medical Center's electronic database of patient files by searching for a group therapy session between. We performed a retrospective chart review of the ratings on the SCARED (Screen for Child Anxiety Related Disorders) scale before and after a mindfulness based intervention in 8-week group therapy. Specifically, a mindfulness deep breathing exercise was performed by participants with the therapist directing to take a deep breath by breathing in through the nose and out through the mouth and letting go of any thoughts.

The control group was from previously reported study by Scales et al. (2018) where patients were included in the study if they were between the ages 6 to 18 years, had a primary diagnosis of SAD or GAD or any other anxiety diagnosis. Patients from both groups were enrolled in the Penn State Hershey Psychiatry cognitive behavioral group therapy in the time frame 07/2016-06//2018 and had completed pre- and post-analysis of SCARED.

The diagnosis of an anxiety disorder was determined by clinical interview by child and adolescent psychologists or therapists based on Diagnostic and Statistical Manual of Mental Disorders (DSM V).

Electronic database searches were conducted by using PubMed, and Medline OVID utilizing keywords: chronic illness, children and adolescents, anxiety, cognitive behavioral therapy, mindfulness.

\section{Procedures}

Child self-report

SCARED, Screen for Child Anxiety Related Emotional Disorders, was the primary tool used to determine improvement in anxiety levels amongst the 
participants. SCARED is a 41-item standardized self-reporting tool that was developed for children and adolescents as well as for parents to screen for anxiety disorders, including General Anxiety Disorder, Separation Anxiety Disorder, Panic Disorder, Social Phobia, and School Phobia (Birmaher et al. 1999). Responses to the 41 items are summed up into a composite score and scores on individual anxiety subscales (Birmaher et al. 1999). A composite score of 25 or greater indicates the presence of an anxiety disorder (Birmaher et al. 1999).

Participants completed a self-report SCARED both on the first and last day of the group and documentation was uploaded into the Electronic Medical Record (EMR). Pre- and post-analysis of SCARED from the participant was obtained from the medical record. Identifiers were destroyed upon retrieval of the data from the medical record and reviewed.

\section{Results}

To determine if Penn State's Pediatric Psychiatry CBGT for Generalized Anxiety Disorders was effective in lowering anxiety scores, we attempted to compare information between the pre- and post- SCARED using t-tests. Due to a high number of participants with chronic illness and anxiety who did not attend the last session to fill out the SCARED or dropped out, statistical analysis could not be performed or compared with the control group previously reported (see Table 1 for sample characteristics and size). This finding tends not to be uncommon for group therapy interventions especially when working with children and adolescents who are either highly anxious and/or live life with a chronic illness given its impact on their overall quality of life socially, emotionally and behaviorally.

Results for the CBGT group were limited given the small sample size. For both participants, there was either a significant self-reported decrease in overall anxiety from pre and post or no change at all. For participant 1, the pre- SCARED score was 9 and the post- SCARED score was 2. For participant 2, the preSCARED score was 24 and the post- SCARED score was 25 (Figure 1).

\section{Discussion}

The literature review showed a limited number of studies comparing these two treatments. In this study, two participants-maintained attendance throughout the seven sessions. Four participants dropped out of the study. One participant with severe anxiety (pre-session SCARED: 34 ) attended only four sessions which could have impeded his participation and another one did not meet inclusion criteria for an anxiety disorder. 
Table 1. Characteristics of Participants in Mindfulness Based Intervention Group

\begin{tabular}{|c|c|c|c|c|c|c|}
\hline Age & Sex & $\begin{array}{c}\text { Number of sessions } \\
\text { attended }\end{array}$ & Diagnosis & $\begin{array}{c}\text { Pre-session } \\
\text { SCARED }\end{array}$ & Post-session SCARED & Outcome \\
\hline 15 & Female & 7 & $\begin{array}{c}\text { Psychological factors affecting } \\
\text { medical conditions }\end{array}$ & $\begin{array}{c}\text { Total Score: } 9 \\
\text { Meaningful subscales: } \\
\text { Social Anxiety: } \\
8 \text { (clinical range) }\end{array}$ & $\begin{array}{c}\text { Total Score: } 2 \\
\text { Subscale scores: } \\
\text { Social Anxiety: } 2\end{array}$ & Did not attend \\
\hline 10 & Male & 0 & No anxiety diagnosis & $\begin{array}{c}\text { Did not meet diagnostic criteria } \\
\text { for participation }\end{array}$ \\
\hline 16 & Male & 4 & Generalized Anxiety Disorder & $\begin{array}{c}\text { Total Score: } \\
34\end{array}$ & Did not attend & Dropped out of study \\
\hline 15 & Female & 0 & Generalized Anxiety Disorder, & Panic Disorder & Did not attend & Dropped out of study \\
\hline 17 & Female & 4 & Generalized Anxiety Disorder & $\begin{array}{c}\text { Total Score: } \\
17\end{array}$ & Did not attend \\
\hline $\begin{array}{c}\text { Total Score: } 24 \\
\text { Meaningful subscales: } \\
\text { Panic Disorder: } \\
8 \text { (clinical range) } \\
\text { Social Anxiety: } \\
8 \text { (clinical range) }\end{array}$ & $\begin{array}{c}\text { Total Score: } 25 \\
\text { Panic Disorder: } \\
8 \text { (clinical range) }\end{array}$ & Dropped out of study \\
\hline
\end{tabular}


Figure 1. SCARED Scores of Active Participants

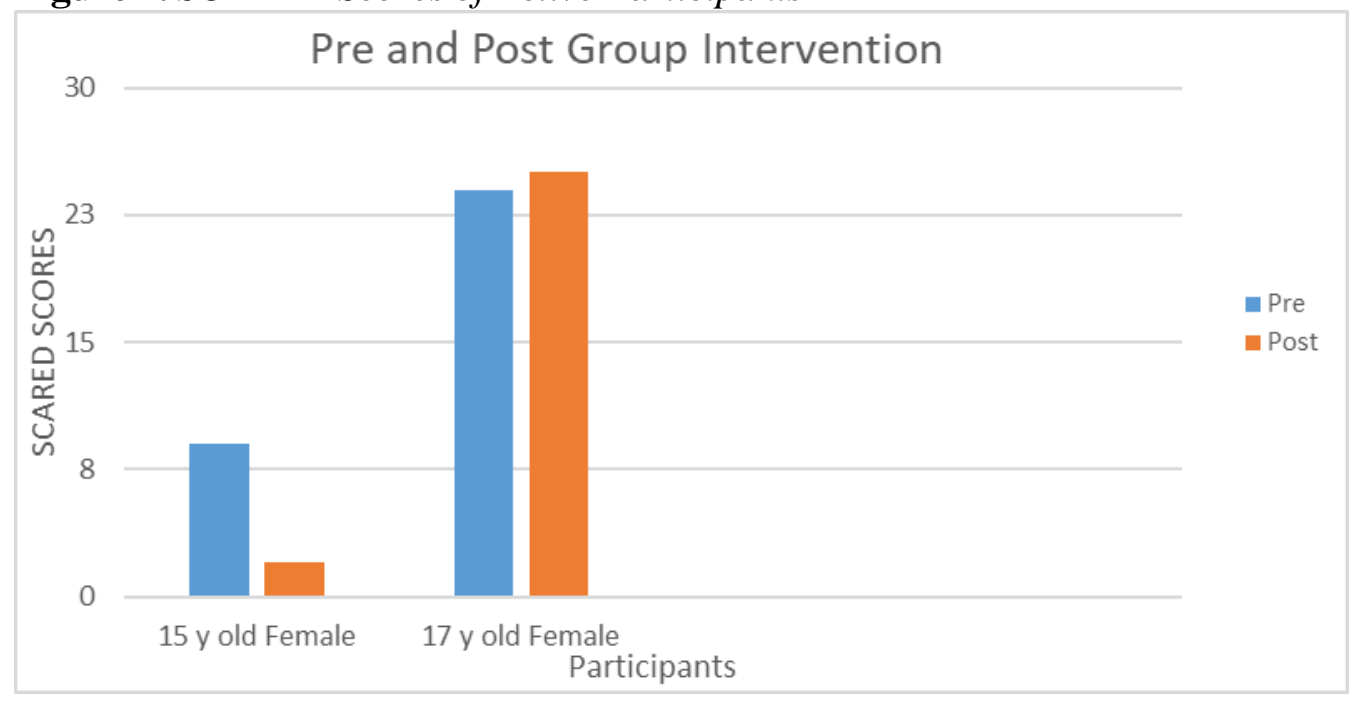

Another factor for the high dropout rate was that the study was held during the summer vacation months of the participants, which could have conflicted with personal schedules.

Our findings for the CBGT control are favorable showing a significant decrease in overall anxiety for most participants and no worsening of anxiety in the remaining participants as determined by pre- and post- intervention anxiety scores.

Our experimental group had a smaller sample size compared to participants who fully completed four or more sessions in our previously published control group. The experimental group also did not complete pre- and post-SCARED documentation within the EMR due to very high dropout rate and non-completion of the final SCARED in the study group that prevented us from being able to perform a meaningful statistical analysis. The experimental mindfulness group will have to be repeated in order to draw any conclusions about the effects of treatment compared to traditional CBT.

The 8-week-therapy groups addressed chronic illness and anxiety disorders in a psychiatric setting at Penn State Hershey. These sessions could have been held at a main medical setting to reduce stigmatization with psychiatric disorders and improve attendance and retention. Attrition rates of children and adolescents in group therapy are high in similar populations and not uncommon for group therapy interventions. Due to the high impact of chronic illness in overall quality of life and medical complications, children and adolescents are impacted socially, emotionally and behaviorally.

\section{Conclusions}

Mindfulness based interventions are part of a new wave of group psychotherapeutic interventions to treat a variety of individuals with anxiety 
whether they have anxiety or anxiety with comorbidities such as chronic illnesses as examined in our present study.

Even given our limited sample size due to the high dropout rate again not uncommon in such groups we were still able to see in our two participants who completed the pre and post testing (a decrease in one of the participants' level of anxiety pre and post group intervention. We believe that will a larger participant base our findings would be even more robust for this population that we examined. That is a future goal of our work.

\section{Acknowledgments}

The authors would like to acknowledge Dr. Sujatha P. Koduvayur for her help with manuscript preparation.

\section{References}

Barlow JH, Ellard DR (2004) Psychoeducational intervenetions for children with chronic disease, parents and siblings: an overview of the research evidence base. Child: Care, Health and Development 30(6): 637-645.

Bennett S, Shafran R, Coughtrey A, Walker S, Heyman I (2015) Psycholgoical interventions for mental health disorders in children with chronic physical illness: a systematic review. Archive of Disease in Childhood 100(4): 300-318.

Birmaher B, Brent DA, Chiappetta L, Bridge J, Monga S, Baugher M (1999) Psychometric properties of the screen for child anxiety related emotional disorders (SCARED): a replication study. Journal of the American Academy of Child and Adolescent Psychiatry 38(10): 1230-1236.

Blocher JB, Fujikawa M, Sung C, Jackon DC, Jones JE (2013) Computer-assisted cognitive behavioral therapy for children with epilepsy and anxiety: a pilot study. Epilepsy Behavior 27(1): 70-76.

Cobham VE, Hickling A, Kimball H, Thomas JH, Scott JG, Middeldorp CM (2019) Systematic review: anxiety in children and adolescents with chronic medical conditions. Journal of American Academy of Child \& Adolescent Psychiatry. DOI: 10.1016/j.jaac.2019.10.010.

Kabat-Zinn J (1994) Wherever You Go, There You Are: Mindfulness Meditation in Everyday Life. New York: Hyperion.

Lazarus RS, Folkman S (1984). Stress Appraisal and Coping. New York: Springer.

LeBlanc LA, Goldsmith T, Patel DR (2003) Behavioral aspects of chronic illness in children and adolescents. Pediatric Clinics of North America 50(4): 859-878.

Merikangas KR, He JP, Burstein M, Swanson SA, Avenevoli S, Cui L, Benjet C, Georgiades K, Swendsen J (2010) Lifetime prevalence of mental disorders in US adolescents: results from the national comorbidity survey replication--adolescent supplement (NCS-A). Journal of the American Academy of Child and Adolescent Psychiatry 49(10): 980-989.

Mokkink LB, van der Lee JH, Grootenhuis MA, Offringa M, Heymans HS (2008) Defining chronic diseases and health conditions in childhood (0-18 years of age): 
national consensus in the Netherlands. European Journal of Pediatrics 167(12): $1441-1447$.

Olson AL, Johansen SG, Powers LE, Pope JB, Klein RB (1993) Cognitive coping strategies of children with chronic illness. Development and Behavioral Pediatrics 14(4): 217-223.

Pinquart M, Shen Y (2011) Anxiety in children and adolescents with chronic physical illnesses: a meta-analysis. Acta Paediatrica 100(8): 1069-1076.

Priya G, Kalra S (2018) Mind-body interactions and mindfulness meditation in diabetes. European Endocrinology 14(1): 35-41.

Reigada LC, Benkov KJ, Bruzzese JM, Hoogendoorn C, Szigethy E, Briggie A, Walder DJ, Warner CM (2013) Integrating illness concerns into cognitive behavioral therapy for children and adolescents with inflammatory bowel disease and co-occurring anxiety. Journal for Specialists in Pediatric Nursing 18(2): 133-143.

Sansone E, Raggi E, D'Amico D, Scaratti C, Grazzi L (2018) Mindulness medittion for chornic migraine in pediatric population: a pilot study. Neurological Sciences 39(Jun): 111-113.

Scales R, Zeiger T, Sims C, Petrovic-Dovat L (2018) Assessing cognitive behavioral therapy groups using SCARED scores for children and adolescents with anxiety disorders. Research Journal of Clinical Pediatrics 2(1): 1-3.

Scholten L, Willemen AM, Grootenhuis AA, Maurice-Stam H, Schuengel C, Last BF (2011) A cognitive behavioral based group intervention for children with a chronic illness and their parents: a multicentre randomized controlled trial. BMC Pediatrics 11(65).

Semple R, Lee J, Miller L (2006) Mindfulness-based cognitive thrapy for depression: A new approach to preventing relapse. In R Baer (Ed.), Mindfulness-Based Treatment Approaches: Clinicians Guide to Evidence Base and Applications, pp. 143-146. Oxford, UK: Elsevier.

Tegethoff MB (2015) Association between mental disorders and psychical diseases in adolescents from a national representative cohort. Psychosomatic Medicine 77(3): 319-332.

Thompson M, Gauntlett-Gilbert J (2008) Mindfulness with children and adolescents: effective application. Clinical Child Pyshcology and Psychiatry 13(3): 395-407.

van Beljouw L, Verhaak P, Prins M, Cuijpers P, Penninx B, Bensing J (2010) Reasons and determinants for not receiving treatment for common mental disorders. Psychiatric Services 61(3): 250-257.

van den Brink G, Stapersma L, El Marroun H, Henrichs J, Szigethy EM, Utens EM, Escher JC (2016) Effectiveness of disease-specific cognitive behavioral therapy on depression, anxiety, quality of life and the clinical course of disease in adolescents with inflammatory bowel disease: study protocol of multicentre randomised controlled trial. BMJ Open Gastroenterology 3(1): 1-10.

Wagner E, Rathus J, Miller A (2006) Mindfulness in dialectical behavior therapy for adolescents. In R Baer (Ed.), Mindfulness-Based Treatment Approaches: Clinicians Guide to Evidence Base and Applications, pp. 143-166. Oxford, UK: Elsevier. 



\title{
Let Master of Public Health Students Experience Statistical Reasoning
}

\begin{abstract}
By Qi Zheng*
Biostatistics is an integral part of any public health student's curriculum. Most masterlevel public health students, lacking undergraduate training in calculus-centered mathematics, are often regarded as unprepared for conceptual knowledge, and hence their biostatistics education is dominated by procedural skills. Quoting classroom-tested examples, this article argues for the feasibility of teaching conceptual knowledge using a first principle-guided, computation-driven hands-on approach. Examples are drawn from an online course in categorical data analysis, and it is shown that making the likelihood function comprehensible is key to imparting successfully a majority of the important abstract concepts encountered in an introductory course in categorical data analysis. Data from end-of-semester course surveys were found to support the proposition that master-level public health students are receptive to conceptual knowledge of biostatistics and are able to appreciate the beauty of statistical reasoning.
\end{abstract}

Keywords: Biostatistics, Recipe method, Video lecture, Categorical data analysis, Likelihood function

\section{Introduction}

Biostatistics is an indispensable tool in public health practice and research, and hence is an integral part of any public health student's curriculum. Masterlevel public health students (commonly known as MPH students) constitute a sizable portion of consumers of today's biostatistics education. However, only recently did this distinct population of students become targets of focused pedagogical research by statistics educators (e.g., Loux et al. 2016). This reflects an increasing awareness among statistics education researchers that students in different disciplines require different statistical curricula and accordingly different statistical pedagogical methods. Among recent examples are statistical educations studies aiming at students in medicine (Bland 2004), in pharmacy (McLaughlin and Kang 2017), in nursing (Schwartz 2014, Shillam et al. 2014), in social work (Marson 2007, Mirick and Davis 2017), and in ecology (McGraw and Chandler 2015).

The present research echoes an earlier, relatively richer literature on statistical education for general non-statistics majors (Snee 1993, Garfield 1995, Stuart 1995, Bradstreet 1996, Moore 1997, Sahai 1990). These early research efforts share an urgent call to shift attention from merely teaching statistical methods to earnestly enabling students to experience substantive statistical reasoning. Bradstreet (1996) went so far as to advocate preceding, if not superseding, statistical methods with statistical reasoning in any introductory statistical courses. While most statistics educators embrace this pedagogical philosophy enthusiastically, scant research exists into the nuts and bolts of how to design an introductory biostatistics course

*Professor, School of Public Health, Texas A\&M University, USA. 
that effectively promotes the teaching of conceptual knowledge, a prerequisite for meaningful statistical reasoning. Even more rarely researched is the teaching of an introductory course in categorical data analysis (CDA), an important sequel to a first introductory biostatistics course (often dubbed Biostats-1) for MPH students. In a meticulously designed survey of the public health research literature, Hayat et al. (2017) found that logistic regression, a leading modeling technique for categorical data, was the most commonly employed data analysis tool in public health research, employed in $38.4 \%$ of the studies that were randomly sampled by the survey's authors. When another important categorical data tool, Poisson regression, was also included in this statistic, categorical data analysis techniques figured in $45.8 \%$ of the sampled public health studies.

Current statistics education research, particularly research aiming at nonstatistics majors, focuses disproportionately on pedagogy assessment. Most existing assessment research took a binary comparison approach, and the investigators seemed to be content with detecting a significant difference between a conventional and a novel pedagogy. This tendency has left a critical gap in current understanding of biostatistics education for non-statistics majors. The following fictitious scenario helps throw this critical gap into sharp relief. In a study of a problem-based approach (Neville 1999) to teaching biostatistics, promising conclusions may be drawn concerning a particular implementation of the problem-based paradigm. But the implementation details are unknown to the reader. The extent to which problem-based learning has been integrated appears to be of no direct concern to the investigators. It is therefore up to the instructors to devise a concrete problem-based approach that can be employed to achieve their teaching goals in a particular setting. Clearly some implementations of the problem-based paradigm will be more effective than others. In other words, the instructors still need to invent the nuts and bolts to allow the problem-based pedagogy to work to their satisfaction, or find the nuts and bolts somewhere else and deftly assemble them according to the instructor's tastes and the students' backgrounds. The following real-world example further underscores the need to fill the foregoing critical gap. The flipped classroom approach is increasingly popular among biostatistics educators (Loux et al. 2016, McGraw and Chandler, 2015, McLaughlin and Kang 2017, Styers et al. 2018). However, a study by Jensen et al. (2015) suggests that the known benefits of the flipped classroom may not be attributable to the flipped classroom per se. Instead, the putative benefits of the flipped classroom may be effected by active learning (Prince 2004, Styers et al. 2018). Such a disagreement about a major teaching strategy highlights the importance of practical implementation details. The effectiveness of the flipped classroom may well depend on a myriad of implementation details, which may in turn depend on the subject matter and the targeted students. The teaching of conceptual knowledge of CDA to MPH students is almost an untrodden realm for pedagogical research, and novel practical details are important in their own right.

The increasing popularity of distance education at public health schools has raised new barriers to teaching conceptual knowledge of biostatistics to MPH students. While the online setting is helpful in imparting application-related procedural knowledge, it does not seem conducive to stimulating students' interest 
in mathematical or statistical reasoning (Brimacombe 2014: p. 4). I first taught an introductory CDA course to an on-campus class of $20 \mathrm{MPH}$ students in the fall semester of 2010. The teaching methods were nearly traditional, and the class used the popular textbook by Agresti (2007). I began teaching the same course online in the fall semester of 2015. Faced with the unfamiliar challenges unique to online teaching, I devised a new teaching approach, but relied on the same textbook. I considerably shifted emphasis to conceptual knowledge, and found the outcomes promising. Using roughly the same materials, e.g., videos, homework problems, I repeated the online course in the fall semesters of 2016, 2017, 2018 and 2019. In total, I taught about $75 \mathrm{MPH}$ students using the new approach.

This paper offers detailed methods that proved effective in catalyzing statistical reasoning among MPH students in my online CDA courses. This novel approach requires the instructor to carefully distinguish between abstract mathematical deduction and first principle-guided statistical thinking. This distinction is important because MPH students are normally weaker in the former due to lack of calculus-centered mathematical training, but they are no less strong in the latter than most other students. In the next section, I describe a computingbased method for teaching Fisher's exact test to MPH students, which epitomizes this important distinction. Afterwards, I delineate an elementary way of teaching the concept of the likelihood function, which lies at the heart of my teaching approach. I then demonstrate how I solidify students' understanding of the likelihood function by showing them how to calculate the deviance using the definition. It is followed by a demonstration of my approach to teaching the concept of the likelihood ratio. I subsequently outline students' responses to the new teaching approach and I conclude my paper by remarks that may help the interested reader to adapt or extend the new teaching approach.

\section{An Elementary Approach to Fisher's Exact Test}

Fisher's exact test should be in every MPH student's repertoire of investigative tools. But due to seeming mathematical and computational complexity, most introductory biostatistics textbooks eschew detailed discussion of Fisher's exact test. For instance, the popular introductory textbook of Pagano and Gauvreau (2000, p. 347) gives students this succinct advice: "Because the computations involved can be arduous, it is not presented in this text. However, a number of statistical software packages perform Fisher's exact test for $2 \times 2$ tables in addition to the chi-square test." On further reflection an instructor may realize that the chi-square test requires far more advanced mathematics than does Fisher's exact test. A rudimentary knowledge of the binomial coefficient, a standard topic in any high school algebra curriculum, is the only prerequisite for imparting the ideas underpinning Fisher's exact test to an MPH student. Furthermore, the widespread availability of powerful statistical packages should unshackle students from tedious computations. An MPH student can acquire a solid understanding of Fisher's exact test by studying the example of a gastroenteritis outbreak following a lunch served in the cafeteria of a US high school. The background context is 
summarized in the same textbook (Pagano and Gauvreau 2000: p. 360) as follows: "Among a sample of 263 students who bought lunch in the school cafeteria on the day in question, 225 ate prepared sandwiches and 38 did not." Table 1 shows the numbers of cases of gastroenteritis in each group.

Table 1. An Outbreak of Gastroenteritis at a US High School

\begin{tabular}{|l|l|l|l|}
\hline \multirow{2}{*}{ Got ill } & Ate sandwich & \multirow{2}{*}{ Total } \\
\cline { 2 - 4 } & Yes & No & $\mathbf{1 1 3}$ \\
\hline Yes & 109 & 4 & $\mathbf{1 5 0}$ \\
\hline No & 116 & 34 & $\mathbf{2 6 3}$ \\
\hline Total & $\mathbf{2 2 5}$ & $\mathbf{3 8}$ & \\
\hline
\end{tabular}

The elegant underlying idea is illustrated by a simple urn model. To facilitate students' learning, I first presented a smaller urn model in which the urn contained just 4 black balls and 2 white balls. And 3 balls were to be sampled. The desired probability was the probability of finding 2 black balls among the 3 sampled, which could be explained via the multiplication rule for independent events. Once students got a handle on this simplified problem, they were asked to consider a larger urn containing 225 black balls and 38 white balls. An imaginary goddess of health decides to randomly choose 150 balls to be protected from harm. What is the probability that she ended up with 34 white balls? Students could write down an expression for that probability, but they used the SAS (2012) statement pdf("hyper",34,263,38,150) to compute the probability (SAS Institute Inc. 2012):

$P(34)=\frac{\left(\begin{array}{c}38 \\ 34\end{array}\right)\left(\begin{array}{l}225 \\ 116\end{array}\right)}{\left(\begin{array}{l}263 \\ 150\end{array}\right)}=3.5 \times 10^{-6}$

This sets the stage for students to deepen their understanding of p-values. A list of the 39 probabilities $P(0), P(1), \ldots, P(38)$ was produced via SAS. It was straightforward for students to see that the right-side $p$-value is $P(34)+\cdots+P(38)=0.00000397$. But the definition of the $\mathrm{p}$-value had to be reviewed before calculating the left-side p-value. It was emphasized that having 8 white balls is more likely to happen than having 34 white balls. Consequently, the left-side p-value is $P(0)+\cdots+P(8)=0.00000125$. Finally, students saw why the (usual) two-sided p-value should be $5.22 \times 10^{-6}$.

This example shows the pedagogical power of first principle-driven statistical reasoning when aided by today's computing technology. To further harness the power of this method of teaching CDA to MPH students, I found it fruitful to focus attention on the likelihood function.

\section{The Likelihood Function is Key to Comprehension}

Because the concept of the likelihood function spawns most other difficult concepts in CDA, I made students in the first three weeks concentrate on acquiring 
an ability to write on paper and code in SAS the log-likelihood function for a simplified logistic regression model, which was adapted from a well-known research problem of beetle deaths caused by a pesticide. In this simplified example six groups of beetles were exposed to a pesticide at different concentrations. Table 2 displays the data.

Table 2. Simplified Data from a Pesticide Experiment

\begin{tabular}{|l|l|l|l|l|l|l|}
\hline Concentration & 10.8 & 11.6 & 12.1 & 12.6 & 13.1 & 13.5 \\
\hline Death & 15 & 24 & 26 & 24 & 29 & 29 \\
\hline Group size & 50 & 49 & 50 & 50 & 50 & 49 \\
\hline
\end{tabular}

Students were asked to demonstrate their understanding of the likelihood function by solving several homework problems derived from this example. Before tackling the homework problems, students learned two crucial facts from a lecture about a similar problem. First, from a graph of the logistic function they learned why the problem required the following logistic model:

logit $[P($ death at concentration $C)]=\beta_{0}+\beta_{1} \times C$

Here $C$ denotes the concentration of the pesticide. To appreciate the logit model (2), students also need to understand the binomial distribution. I discuss the binomial distribution in an introductory biostatistics course, which is a prerequisite for the CDA course. Because the binomial coefficient is a standard topic in any high school algebra curriculum, the binomial distribution may also be smoothly introduced in a CDA course.

Once the role of the likelihood function is explained, students quickly understand why multiplying factors free from the two parameters $\beta_{0}$ and $\beta_{1}$, e.g., the binomial coefficients, can be dropped from the likelihood function. For example, students can easily write down the term in the likelihood function contributed by the first group of beetles as

$$
\left(\frac{1}{1+e^{-\left(\beta_{0}+10.8 \beta_{1}\right)}}\right)^{15}\left(\frac{1}{1+e^{\left(\beta_{0}+10.8 \beta_{1}\right)}}\right)^{35}
$$

Figure 1 shows this expression written by a student. After recalling the monotonic increasing property of the logarithmic function, students were receptive to the fact that maximizing the log-likelihood function is the same as maximizing the likelihood function itself. Students were further reminded of the following properties of the logarithmic function they learned in high school.

$$
\begin{aligned}
& \log (a \times b)=\log (a)+\log (b) \\
& \log \left(\frac{a}{b}\right)=\log (a)-\log (b) \\
& \log \left(e^{x}\right)=x \\
& \log \left(a^{b}\right)=b \times \log (a)
\end{aligned}
$$




$$
\begin{aligned}
& \log \left(\frac{1}{a}\right)=-\log (a) \text { with } \log (1)=0 \\
& \frac{e^{a}}{e^{b}}=e^{a-b} \text { with } e^{0}=1
\end{aligned}
$$

Figure 1. A Student's Handwritten Work Deriving the Expression in Equation (3)

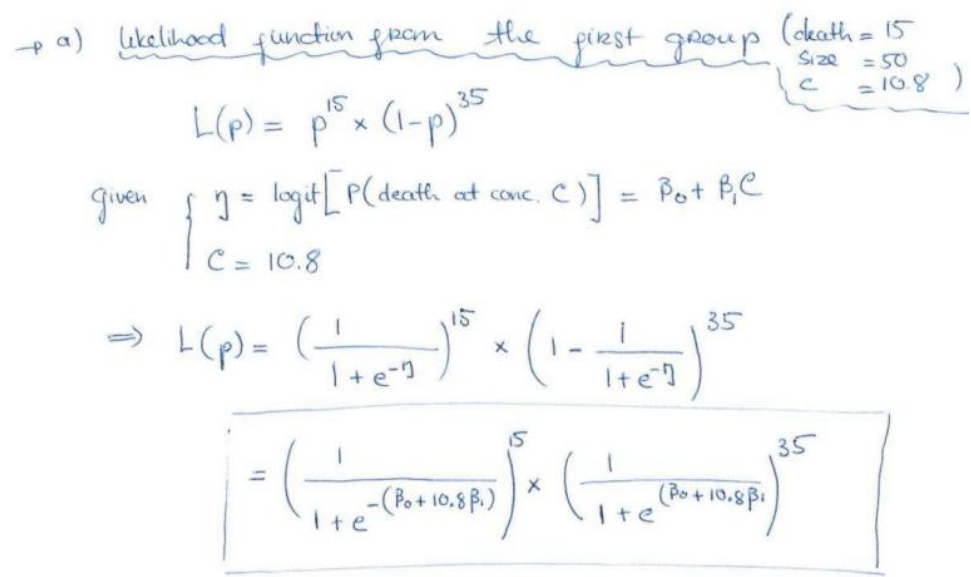

Note that the student first wrote the linear predictor $\eta$ before recasting it as a component probability of the likelihood function.

Applying these properties, students were able to transform a likelihood function to the corresponding log-likelihood function and then code it using the SAS fcmp procedure. Figure 2 shows a student's SAS rendition of the loglikelihood function for the beetle example. Acquiring an ability to code the loglikelihood function for the beetle example was a milestone for MPH students learning CDA, because they began to relish concretizing abstract concepts by an accessible hands-on approach, thereby bolstering confidence in their ability to master theoretical basics of CDA. Finding values of $\beta_{0}$ and $\beta_{1}$ that maximize the likelihood function (they are called maximum likelihood estimates, or MLEs) is beyond the scope of an introductory CDA course, and students were forthrightly informed that a statistical software package like SAS uses sophisticated iterative algorithms to achieve that feat. This only further piqued students' curiosity. Students obtained MLEs of $\beta_{0}$ and $\beta_{1}$ with SAS proc logistic, and then used them to verify the maximum value of the log-likelihood function by comparing their result with SAS output. (See Figure 3 for a student's actual work.) Through this process students developed an intuitive sense about the meaning of an MLE, the existence and uniqueness of MLEs. This exercise paved the way for some more challenging concepts.

\section{A Firsthand View of the Deviance}

As the concept of the likelihood is a key pillar of conceptual knowledge of CDA methods, students should be given ample opportunities to view it from different angles. When all predictors are categorical in a model, the likelihood function can appear utterly different from the one student saw in the previous 
example. The following computational exercises, based on the well-known adolescent sexual behavior study (Agresti 2007: 113), aims to solidify students' understanding of the likelihood function, which also opens doors for students to grasp another elusive concept, the deviance. Table 3 reproduces the data for ease of reference.

Table 3. Data on Teenagers and Sex

\begin{tabular}{|l|l|l|l|}
\hline \multirow{2}{*}{ Race } & \multirow{2}{*}{ Gender } & Intercourse \\
\cline { 3 - 4 } & & Yes & No \\
\hline \multirow{2}{*}{ White } & Male & 43 & 134 \\
\cline { 2 - 4 } & Female & 26 & 149 \\
\hline \multirow{2}{*}{ Black } & Male & 29 & 23 \\
\cline { 2 - 4 } & Female & 22 & 36 \\
\hline
\end{tabular}

Figure 2. A Student's SAS Rendition of the Log-Likelihood Function for the Beetle Example. A Pair of Testing Values were used to Test whether the SAS Code was Executable

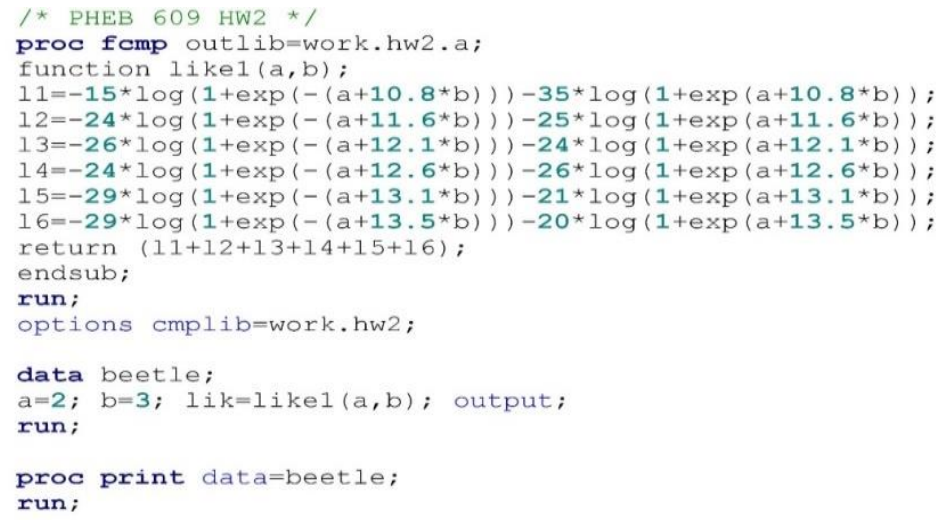

After studying a similar example from a video lecture, students understand the rationale for adopting the logit model

$\operatorname{logit}(P($ intercourse $))=\beta_{0}+\beta_{1} \times$ Race $+\beta_{2} \times$ Gender

Here both Race and Gender are dummy variables. Race takes the value zero when the subject is black, and unity when the subject is white. Similarly, Gender equals zero when the subject is female, and unity when the subject is male. Although this model bears close resemblance to the previous logit model (2), students took a fresh look at the likelihood out of curiosity about the two dummy variables. For example, in the while-female scenario the linear component is $\beta_{0}+\beta_{1}$. Therefore, the likelihood function should include the expression: 
$\left(\frac{1}{1+\exp \left(-\left(\beta_{0}+\beta_{1}\right)\right)}\right)^{26} \times\left(\frac{1}{1+\exp \left(\beta_{0}+\beta_{1}\right)}\right)^{149}$

which should be in the following form when it appears in the corresponding loglikelihood function:

$-26 \log \left(1+\exp \left(-\left(\beta_{0}+\beta_{1}\right)\right)-149 \log \left(1+\exp \left(\beta_{0}+\beta_{1}\right)\right)\right.$

Figure 3. A Student Verifies the Maximized Value of a Log-Likelihood Function that SAS Produces

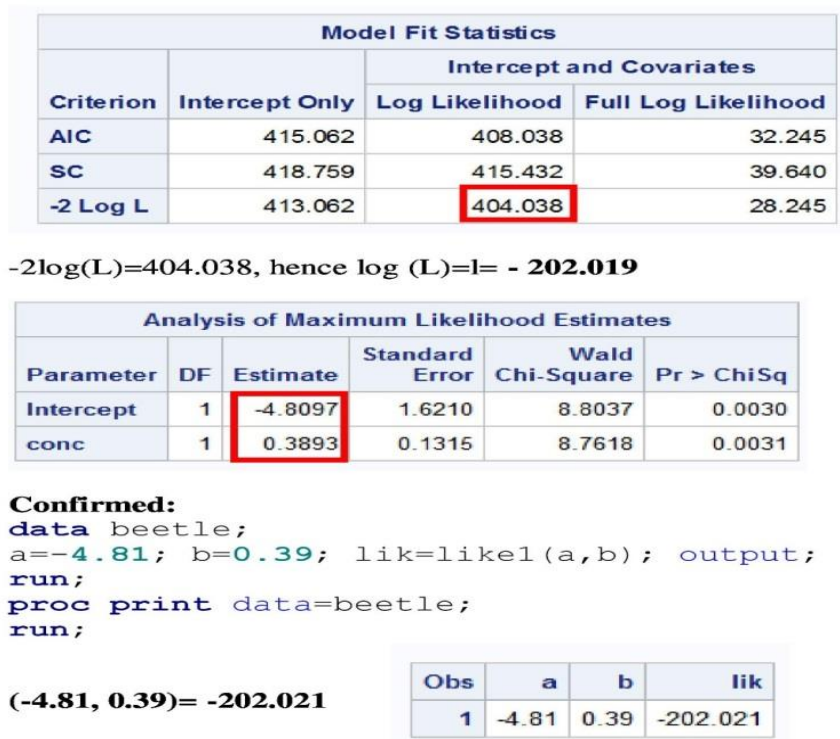

Note that the student uses a pair of parentheses to signify the operation of division by 2 , which is non-standard.

This algebraic exercise further familiarized students with the likelihood principle. Figure 4 shows how one student coded the log-likelihood function and how she used it to confirm the value that the log-likelihood function should assume when the three arguments of the function coincide with the maximum likelihood estimates of the three model parameters.

At this stage the concept of the saturated model can be introduced. In the context of a simple model like (5), students would find the concept quite approachable. For example, in the white-female scenario, the probability of intercourse should be $26 /(26+149)$ under the saturated model, for the model to be "closest" to data. Thus, the log-likelihood function should contain the quantity $26 \log (26 / 175)+149 \log (149 / 175)$. The maximized $\log$-likelihood value for the saturated model, denoted by $l_{\text {sat }}$, is easier for students to calculate than $l_{\text {model }}$, the maximized log-likelihood value for the actual model - the logit model (5) in the present context. Figure 5 shows a student's calculation of $l_{\text {sat }}$. The definition of the deviance:

$D=-2\left(l_{\text {model }}-l_{\text {sat }}\right)$ 
can now be introduced using a simple example like this one. A student's work calculating the deviance of the model (5) is shown is Figure 6.

Figure 4. A Student's Work to Evaluate the Log-Likelihood Function at the Maximum Likelihood Estimates of the Three Model Parameters
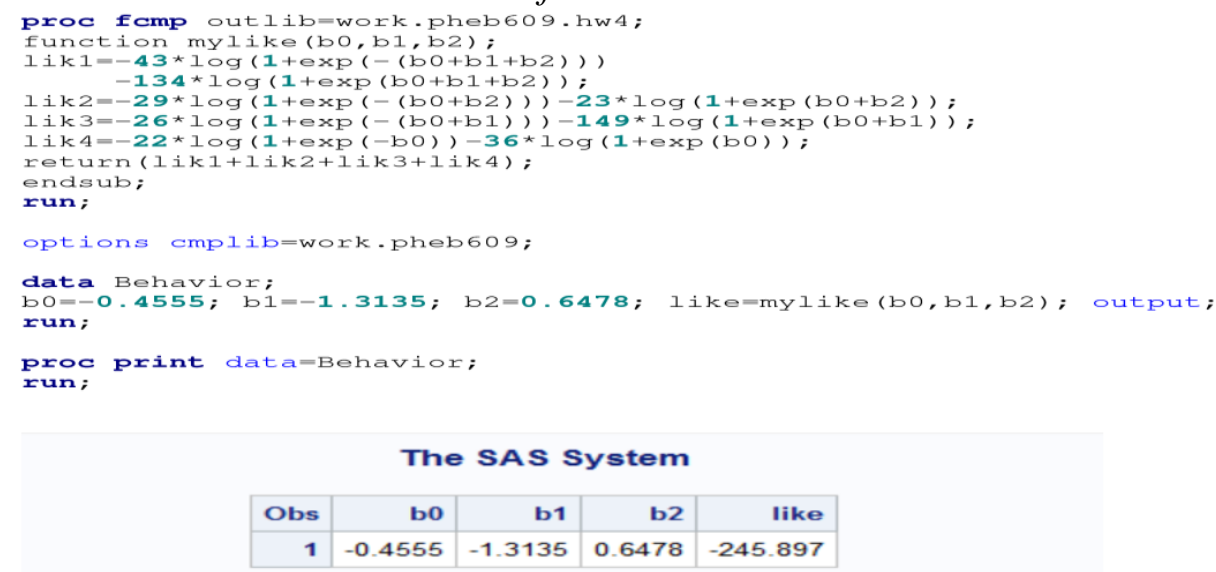

Figure 5. A Student's Work Showing the Calculation of the Maximized LogLikelihood Value for the Saturated Model, $l_{\text {sat }}$, in the Adolescent Sexual Behavior

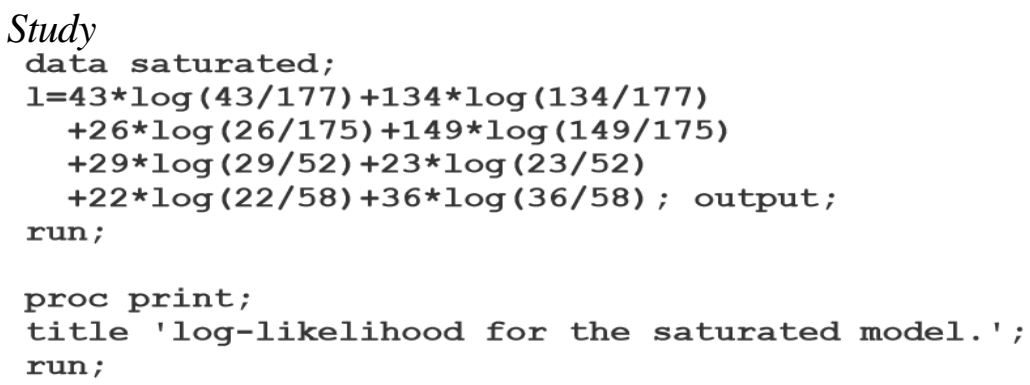

log-likelihood for the saturated model.

\begin{tabular}{|r|r|}
\hline Obs & $\mathbf{1}$ \\
\hline 1 & -245.868 \\
\hline
\end{tabular}

Figure 6. A Student's Work Showing the Calculation of the Deviance of the Logit Model (5)

$$
\begin{aligned}
& \text { j) Deviance }=-2\left(l_{\text {modl }}-l_{\text {sat }}\right)= \\
& -2(-245.897-(-245.868))=0.058
\end{aligned}
$$

\section{Anatomizing the Likelihood Ratio Test}

The likelihood ratio (LR) test is another bewildering concept for MPH students. However, once they digest the concept of the likelihood function, they can explore and demystify the LR test. In my CDA classes, students also used the 
beetle example to see how the LR principle works in testing the null hypothesis $H_{0}: \beta_{0}=0$ against the alternative hypothesis $H_{1}: \beta_{0} \neq 0$. Due to their newly acquired appreciation of the likelihood function, students now readily saw the precise meaning of the null hypothesis. By setting $\beta_{1}=0$ in the expression (3), they obtained the expression:

$\left(\frac{1}{1+e^{-\beta_{0}}}\right)^{15}\left(\frac{1}{1+e^{\beta_{0}}}\right)^{35}$

as the contribution of the first group of beetles to the likelihood function under $H_{0}$. Using the elementary properties of the logarithmic function in equation (4), students were able to show that the log-likelihood function under $H_{0}$ is of the form

$-147 \log \left(1+e^{-\beta_{0}}\right)-151 \log \left(1+e^{\beta_{0}}\right)$.

Figure 7 displays a student's derivation of the above likelihood function. At this stage, a homework problem asked students to plot the expression (10) as a function of $\beta_{0}$, and to use SAS proc logistic to find $\widehat{\beta}_{0}$ (by specifying an interceptonly model) that maximizes the expression (10). This exercise gave students a chance to visualize a log-likelihood function, enhancing their understanding of the concept of maximum likelihood estimates. Students were now in a position to grasp the rationale for forming the ratio

$\frac{L_{0}}{L_{1}}=\frac{\text { maximized value of likelihood without } \beta_{1}}{\text { maximized value of likelihood with } \beta_{1}}$

Figure 7. A Student's Derivation of the Log-Likelihood Function Given in Equation (10)

$$
\begin{aligned}
& \left(\frac{1}{1+\mathrm{e}^{-\beta_{0}}}\right)^{15} *\left(\frac{1}{1+\mathrm{e}^{\beta_{0}}}\right)^{35} \\
& \left(\frac{1}{1+\mathrm{e}^{-\beta_{0}}}\right)^{24} *\left(\frac{1}{1+\mathrm{e}^{\beta_{0}}}\right)^{25} \\
& \left(\frac{1}{1+\mathrm{e}^{-\beta_{0}}}\right)^{26} *\left(\frac{1}{1+\mathrm{e}^{\beta_{0}}}\right)^{24} \\
& \left(\frac{1}{1+\mathrm{e}^{-\beta_{0}}}\right)^{24} *\left(\frac{1}{1+\mathrm{e}^{\beta_{0}}}\right)^{26} \\
& \left(\frac{1}{1+\mathrm{e}^{-\beta_{0}}}\right)^{29} *\left(\frac{1}{1+\mathrm{e}^{\beta_{0}}}\right)^{21} \\
& \frac{\left(\frac{1}{1+\mathrm{e}^{-\beta_{0}}}\right)^{29} *\left(\frac{1}{1+\mathrm{e}^{\beta_{0}}}\right)^{20}}{\left(\frac{1}{1+\mathrm{e}^{-\beta_{0}}}\right)^{147} *\left(\frac{1}{1+\mathrm{e}^{\beta_{0}}}\right)^{151}} \\
& =-147 * \log \left(1+\mathrm{e}^{-\beta_{0}}\right)-151 * \log \left(1+\mathrm{e}^{\beta_{0}}\right)
\end{aligned}
$$


Note that the student first derives the likelihood function and then translates it to the log-likelihood function. An equality sign is loosely employed to signify the log-transform.

Because now students saw this ratio as a means of comparing two probabilities, they appreciated the idea that a close to unity LR statistic suggests non-significance of the parameter $\beta_{1}$. Students only needed to accept one theoretical result to see the whole picture: the quantity $-2 \times \log \left(L_{0} / L_{1}\right)$ approximately obeys a chi-squared distribution with one degree of freedom. Using the machinery they had already built, e.g., SAS code for the restricted and unrestricted $\log$-likelihood functions, students computed $L_{0}$ and $L_{1}$ easily. They then obtained the LR test statistics and compared it with SAS output. At this point the equation (11) served as a springboard for introducing students to the concept of the deviance. The rationale for the deviance is similar to the LR principle with which the students were already familiar.

The above learning process paved the way for students to understand the concept of a likelihood ratio confidence interval (CI). In a homework assignment based on the data given in Table 3, students were asked to determine whether a particular parameter value $\beta_{2}^{*}=2.345$ should be inside or outside an LR-based $95 \% \mathrm{CI}$ for $\beta_{2}$. This otherwise difficult goal was made reachable to students by a brief discussion about the following $\Lambda$ quantity:

$\Lambda\left(\beta_{2}^{*}\right)=\frac{\max \operatorname{over}_{\beta_{0}, \beta_{1}} L\left(\beta_{0}, \beta_{1}, \beta_{2}^{*}\right)}{\max \operatorname{over}_{\beta_{0}, \beta_{1}, \beta_{2}} L\left(\beta_{0}, \beta_{1}, \beta_{2}\right)}$

Due to their hands-on experience with likelihood functions, students at this point immediately understood the meaning of the quantity in the denominator, despite the strange mathematical notation that were unfamiliar to most students prior to their enrollment in the course. The quantity in the numerator was also easily explainable conceptually, but how to make it tangible? My solution was to let students use the offset option available in SAS proc logistic (Figure 8). This may seem an excessive burden on MPH students at first glance, but it is within their grasp. Students already grasped the concept of an offset in a preceding lecture about Poisson regression. The unconventional use of the offset only enhances students' understanding of the concept. Because the rationale for equation (12) is similar to that for equation (11), students readily saw that if $-2 \log \left(\Lambda\left(\beta_{2}^{*}\right)>\chi_{1,0.05}^{2}=3.8415\right.$, then $\beta_{2}^{*}$ should be outside the $95 \%$ CI for $\beta_{2}$. In this exercise students found that:

$-2 \log \Lambda(2.345)=541.996-491.795=50.201$.

So, students concluded that the point $\beta_{2}^{*}=2.345$ should be outside a $95 \%$ likelihood ratio $\mathrm{CI}$ for $\beta_{2}$, which they diligently checked against SAS output. A student succinctly summarized this reasoning process in Figure 9. 
Figure 8. A Student's SAS Work to Extract from SAS Output the Constrained Likelihood Value that Corresponds to the Numerator in the Likelihood Ratio Defined by Equation (12)

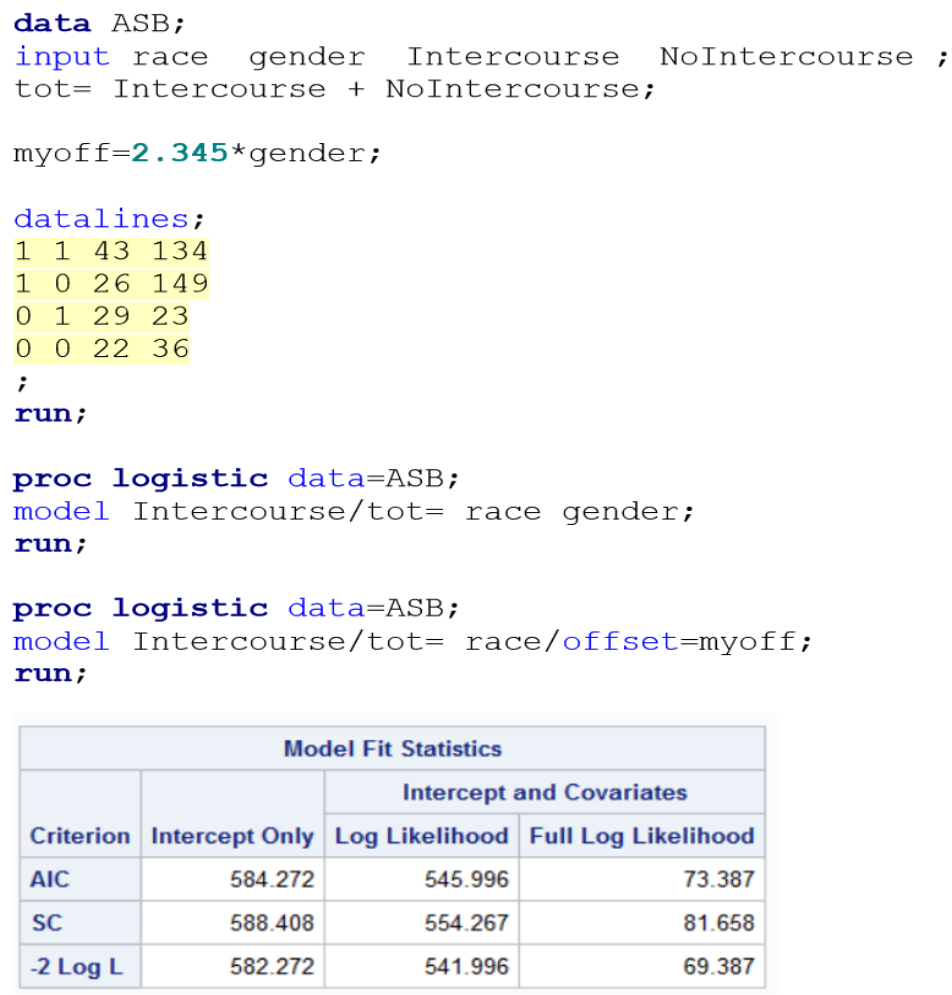

Figure 9. A Student's Demonstration of Why a Particular Point Should Be Outside the $95 \%$ Confidence Interval for the Parameter $\beta_{1}$

$$
95 \% \mathrm{CI} \rightarrow \chi_{1,0.05}^{2}=3.842
$$

The offset is

$$
\text { myof }=2.345^{*} \text { male; }
$$

$$
-2 \log \Lambda=541.996-491.795=50.201>3.842
$$

$\rightarrow-2 \log \Lambda$ is larger than the critical value, therefore the point is outside of the $\mathrm{CI}$

\section{Evaluation by Students}

The novel approach has been well received by a great majority of students in all five CDA classes that I taught in the past five years. Students particularly savored the triumphant moment when they understood how a once-unfathomable statistical package like SAS actually solved a particular problem. In contrast to the 2010 class in which I adopted a more or less traditional approach, the new 
approach generated more enthusiasm and better outcomes as measured by exam results and student evaluations. Because I myself graded all homework assignments and examinations, students' test performance may not be an objective yardstick to evaluate the effectiveness of the new approach. However, the school's routine end-of-semester course surveys provide somewhat objective clues to the new approach's effectiveness. In the fall of 2017, over 400 responses were collected on each item in the end-of-semester course surveys by the Department of Epidemiology and Biostatistics. The average scores based on such a large sample provide a benchmark against which the new approach can be assessed.

A course survey comprises about 20 assertions that are not targeted to a specific course. The students respond to each assertion by choosing an integer score between 1 and 5. A score of "1" indicates that the student strongly disagrees with the statement, while a score of " 5 " signifies the student's strong agreement with the assertion. Responses to five of the assertions recorded for the five CDA classes are summarized in Table 4.

Response rates varied from $45 \%$ to $82 \%$. These five assertions are selected because they may shed light on students' attitude toward the new approach by which I taught the five CDA classes. For example, responses to the second assertion in Table 4, "On the whole, the information learned in this course was valuable to me," could register students' opinions about learning conceptual knowledge and statistical reasoning. The third assertion, "The instructor stimulated my interest in the subject" measures students' enthusiasm about the course content, which depended on the ways the course content was delivered. The fourth assertion, "The instructor gave clear presentations," measures how easily students digest the course content, which in the last five surveys would also indicate students' ability to understand abstract concepts and experience meaningful statistical reasoning.

Table 4. Summary of Student Evaluation

\begin{tabular}{|l|l|l|l|l|l|l|}
\hline Year & PHEB17f & $\mathbf{2 0 1 5}$ & $\mathbf{2 0 1 6}$ & $\mathbf{2 0 1 7}$ & $\mathbf{2 0 1 8}$ & $\mathbf{2 0 1 9}$ \\
\hline Class size & $\sim 400$ & $\mathbf{1 3}$ & $\mathbf{7}$ & $\mathbf{1 1}$ & $\mathbf{2 0}$ & $\mathbf{2 4}$ \\
\hline \multirow{2}{*}{ A1 } & \multirow{2}{*}{4.28} & $\begin{array}{l}3.88 \\
(0.62)\end{array}$ & $\begin{array}{l}5.00 \\
(0.07)\end{array}$ & $\begin{array}{l}4.56 \\
(0.22)\end{array}$ & $\begin{array}{l}4.22 \\
(0.72)\end{array}$ & $\begin{array}{l}4.24 \\
(0.53)\end{array}$ \\
\hline \multirow{2}{*}{$\boldsymbol{A 2}$} & \multirow{2}{*}{4.41} & $\begin{array}{l}3.71 \\
(0.55)\end{array}$ & $\begin{array}{l}5.00 \\
(0.07)\end{array}$ & $\begin{array}{l}4.56 \\
(0.14)\end{array}$ & $\begin{array}{l}4.44 \\
(0.22)\end{array}$ & $\begin{array}{l}4.41 \\
(0.28)\end{array}$ \\
\hline \multirow{2}{*}{$\boldsymbol{A 3}$} & \multirow{2}{*}{4.11} & $\begin{array}{l}3.88 \\
(1.00)\end{array}$ & $\begin{array}{l}5.00 \\
(0.07)\end{array}$ & $\begin{array}{l}4.56 \\
(0.22)\end{array}$ & $\begin{array}{l}4.33 \\
(0.62)\end{array}$ & $\begin{array}{l}4.12 \\
(0.74)\end{array}$ \\
\hline \multirow{2}{*}{$\boldsymbol{A 4}$} & \multirow{2}{*}{4.14} & $\begin{array}{l}3.50 \\
(0.44)\end{array}$ & $\begin{array}{l}4.75 \\
(0.19)\end{array}$ & $\begin{array}{l}4.50 \\
(0.71)\end{array}$ & $\begin{array}{l}4.22 \\
(0.81)\end{array}$ & $\begin{array}{l}4.12 \\
(0.74)\end{array}$ \\
\hline \multirow{2}{*}{$\boldsymbol{A 5}$} & \multirow{2}{*}{4.34} & $\begin{array}{l}4.25 \\
(0.83)\end{array}$ & $\begin{array}{l}5.00 \\
(0.07)\end{array}$ & $\begin{array}{l}4.63 \\
(0.10)\end{array}$ & $\begin{array}{l}4.67 \\
(0.05)\end{array}$ & $\begin{array}{l}4.41 \\
(0.23)\end{array}$ \\
\hline
\end{tabular}

PHEB17f: Average scores based on over 400 responses collected by the Department of Epidemiology and Biostatistics in the fall of 2017.

A1: Assertion 1, "On the whole, this was a good course." 
A2: Assertion 2, "On the whole, the information learned in this course was valuable to me."

A3: Assertion 3, "The instructor stimulated my interest in the subject."

A4: Assertion 4, "The instructor gave clear presentations."

A5: Assertion 5, "On the whole this is a good instructor."

The parenthesized numbers are p-values based on the one-sample Wilcoxon test comparing scores of a given year with the corresponding departmental average scores based on over 400 responses collected in the fall of 2017.

As the average scores in Table 4 suggest, the introduction of the new teaching approach was in the main a success. Most MPH students in the five CDA classes showed a favorable attitude toward conceptual knowledge of biostatistics, and they evinced a remarkable ability to digest abstract concepts and appreciate the beauty of statistical reasoning. To help the reader assess the evidence, the one-sample Wilcoxon test was applied to the student survey responses with the resulting pvalues exhibited in Table 4. This case study involves about 75 students, and some caveats should be noted. First, the five classes were taught sequentially by a single instructor, and the instructor's accumulating experience may interfere with possible differential effects between the two approaches. But the four online classes used the same video files and similar homework and examination problems, the effect of such interference may be minimal. Second, as in any survey, there was a considerable number of non-respondents in each class. A student's reason for not participating in a course survey has not been accounted for. Lastly, a PhD candidate registered for one of my CDA classes. Because the surveys were anonymous, this possible respondent cannot be excluded.

\section{Discussion and Conclusions}

Biostatistics is inherently laden with abstract concepts that are hurdles to most MPH students. While today's biostatistics instructors for MPH students are increasingly aware of the importance of conceptual knowledge, their efforts to weave conceptual knowledge and statistical reasoning into an MPH biostatistics curriculum are often hampered by a lack of easily accessible case-studies. This paper offers detailed, classroom-tested examples that may act as a springboard for improving MPH biostatistics education across public health schools. In particular, these examples may help inexperienced instructors resist the temptation to resort to what Lee (1999: p. 194) dubbed a recipe approach, when MPH students' lack of an adequate mathematical background looms like an insurmountable obstacle.

The need for conceptual statistical knowledge in MPH students' education has not been adequately debated at public health schools, partly because MPH students were rarely able to articulate such a need. For example, in more than 20 end-ofsemester course surveys asking for ways to improve biostatistics teaching, no student expressed an interest in learning conceptual knowledge. But when I taught conceptual statistical knowledge by this new approach, most students were quick to recognize the importance of learning it. Procedural skills taught without 
imparting adequate underlying conceptual knowledge can be harmful to the unwary student. Moreover, teaching procedural skills as if they were recipes stifles easily a student's interest in learning.

The novel hands-on approach outlined here can effectively pique MPH students' interest in learning statistical reasoning in a CDA course. This approach is anchored in two observations. First, from a would-be public health researcher's or practitioner's point of view, most of the abstract concepts are best understood by appealing to first principles. To them, rigorous mathematical formulations of these concepts are nonessential, if not superfluous. However, MPH students find learning the essence of these concepts intellectually exhilarating and conducive to fruitful statistical applications. Luckily, these concepts are often explicable using high school mathematics. Second, these concepts can be rendered tangible by simple computer experiments, and teaching of the necessary computer coding skill can be seamlessly integrated into a CDA course. The likelihood function is central to successfully imparting conceptual statistical knowledge to MPH students in a CDA class. Despite lacking calculus-centric mathematical training as an undergraduate, most MPH students are receptive to fundamental statistical concepts derived from the likelihood function, once these concepts are rendered tangible by concrete numerical examples. Verifying results of a major statistical package through writing simple computer code is especially conducive to stimulating an MPH student's interest in learning conceptual statistical knowledge. The fine distinction between general cognitive ability and high-order mathematical sophistication is often underappreciated by biostatistics educators teaching MPH students.

The computational exercises quoted and others not presented here lie at the heart of the proposed approach to teaching CDA to MPH students. These exercises help students concretize abstract statistical concepts and basic principles, compelling them to participate in a hands-on process of constructing their own statistical knowledge (Garfield 1995). Computing is woven into these exercises, but it is meant for learning statistical reasoning, not for implementing statistical recipes. Such a hands-on approach bolsters students' confidence by making conceptual knowledge accessible to them, which shape not only how enthusiastically MPH students learn biostatistics, but also how deftly they apply biostatistics in their public health practice and research after graduation. Finally, note that the choice of the SAS software was largely due to its popularity among epidemiologists, and the instructor may choose other software platforms like the $\mathrm{R}$ software to serve the same purpose (R Core Team 2017). It is hoped that this unique approach can be adapted to teach other specialized branches of biostatistics, e.g., the analysis of longitudinal data.

\section{References}

Agresti A (2007) An introduction to categorical data analysis. $2^{\text {nd }}$ ed. Hoboken, New Jersey: John Wiley \& Sons, Inc.

Bland JM (2004) Teaching statistics to medical students using problem-based learning: the Australian experience. BMC Medical Education 4(31). 
Bradstreet TE (1996) Teaching introductory statistics courses so that non-statisticians experience statistical thinking. The American Statistician 50(1): 69-78.

Brimacombe MB (2014) Biostatistical and medical statistics graduate education. BMC Medical Education 14(18).

Garfield J (1995) How students learn statistics. International Statistical Review 63(1): 2534.

Hayat MJ, Powell A, Johnson T, Cadwell BL (2017) Statistical methods used in the public health literature and implications for training of public health professionals. PLoS ONE 12(6): e0179032.

Jensen JL, Kummer TA, Godoy PD (2015) Improvement from a flipped classroom may simply be the fruits of active learning. CBE Life Sciences Education 14(1): 5.

Lee C (1999) Computer-assisted approach for teaching statistical concepts. Computers in the Schools 16(1): 193-208.

Loux TM, Varner SE, VanNatta M (2016) Flipping an introductory biostatistics course: a case study of student attitudes and confidence. Journal of Statistics Education 24(1): $1-7$.

Marson SM (2007) Three empirical strategies for teaching statistics. Journal of Teaching in Social Work 27(3/4): 199-212.

McGraw JB, Chandler JL (2015) Flipping the biostatistics classroom, with a twist. Bulletin of the Ecological Society of America 96(2): 375-383.

McLaughlin JE, Kang I (2017) A flipped classroom model for a biostatistics short course. Statistics Education Research Journal 16(2): 441-453.

Mirick RG, Davis A (2017) Making meaning of MSW students' statistical ability: the role of self-efficacy and knowledge-based assessment. Journal of Social Work Education 53(2): 212-221.

Moore DS (1997) New pedagogy and new content: the case of statistics. International Statistical Review 65(2): 123-165.

Neville AJ (1999) The problem-based learning tutor: teacher? Facilitator, evaluator? Medical Teacher 21(4): 393-401.

Pagano M, Gauvreau K (2000) Principles of biostatistics. $2^{\text {nd }}$ ed. Duxbury: Chapman and Hall/CRC.

Prince M (2004) Does active learning work? A review of the research. Journal of Engineering Education 93(3): 223-231.

$\mathrm{R}$ Core Team (2017) $R$ : A language and environment for statistical computing. Vienna, Austria: R Foundation for Statistical Computing.

Sahai H (1990) Some problems of teaching an introductory biostatistics course to graduate students in health sciences: coping with the diversity of student aptitudes, interests and objectives. The Statistician 39(4): 341-347.

SAS Institute Inc. (2012) SAS/STAT Software. Version 9.4. Cary, NC.

Schwartz TA (2014) Flipping the statistics classroom in nursing education. Journal of Nursing Education 53(4): 199-206.

Shillam CR, Ho G, Commoodore-Mensah Y (2014) Online biostatistics: evidence-based curriculum for master's nursing education. Journal of Nursing Education 53(4): 229232.

Snee RD (1993) What's missing in statistical education? The American Statistician 47(2): 149-154.

Stuart M (1995) Changing the teaching of statistics. The Statistician 44(1): 45-54.

Styers ML, Van Zandt PA, Hayden KL (2018) Active learning in flipped life science courses promotes development of critical thinking skills. CBE Life Sciences Education 17(3): 39. 